\title{
Steel sheathed cold-formed steel framed shear walls subjected to lateral and gravity loading
}

\author{
J. DaBreo, N. Balh, C. Ong-Tone and C.A. Rogers* \\ Department of Civil Engineering, McGill University, Montreal, Canada
}

${ }^{*}$ Corresponding author

Tel. 514 398-6449

Fax.514 398-7361

colin.rogers@mcgill.ca

Department of Civil Engineering

McGill University

Macdonald Engineering Building

817 Sherbrooke Street West

Montreal, QC, Canada, H3A 0C3 


\begin{abstract}
The design of steel sheathed cold-formed steel (CFS) framed shear walls is not addressed in Canadian design standards. A program of displacement based loading tests was carried out on single-storey shear walls of various configurations to investigate their performance and to establish a comprehensive database of information. The walls, which were subjected to lateral loading and combined lateral plus gravity loading, differed in sheathing thickness, screw fastener detailing, framing thickness, aspect ratio and framing reinforcement. The performance under loading was directly related to the sheathing connection pattern; however, when the framing elements were not blocked tension field forces resulted in significant damage to the chord studs. Details of the test program and general results are presented in this paper.
\end{abstract}

Keywords : shear wall, cold-formed steel, panel, lateral loading, connections, shear buckling, tension field. 


\section{Introduction}

Cold-formed steel (CFS) framed structures may be constructed using shear walls or strap walls, among other systems, to provide lateral stability and strength. The design of wood sheathed and strap braced CFS framed shear walls has been addressed in Canada through the American Iron and Steel Institute (AISI) North American Standard for Cold-Formed Steel- Lateral Design S213 [1], which is referenced for use by the Canadian Standards Association (CSA) S136 North American Specification for the Design of Cold-Formed Steel Structural Members [2], which in turn is referenced by the National Building Code of Canada (NBCC) [3]. The codified design approaches for wood sheathed CFS framed shear walls [4-7] and strap braced walls [8-11] under lateral loading were developed using the results of extensive testing as well as the response obtained from dynamic analyses of representative buildings subjected to recorded and simulated ground motions. This paper presents the related test program for steel sheathed CFS framed shear walls [12-14], the results of which are to be used to formulate a design method. The initial phase of the research program involved the testing of 54 single-storey shear walls under lateral loading (18 wall configurations) [12-13] followed by a second phase of 14 shear wall specimens (8 wall configurations) tested under combined gravity and lateral loading [14]. The objective of the testing was to establish a comprehensive database of information on steel sheathed CFS framed shear walls by combining the data of the test program, described herein, with US test data from similarly constructed walls [15-19]. Once complete, the intent is to rely on this database to develop a design method and to derive key design parameters for steel sheathed shear walls. This design method and its corresponding design parameters, which are presented in the paper by Balh et al. [20], are based on the same test wall data analysis methodology used to determine the shear resistance 
values presently available in the AISI S213 Standard [1] for wood sheathed CFS framed shear walls, i.e. the equivalent energy elastic plastic analysis approach [6].

The scope of study involved the monotonic and reversed cyclic displacement based loading of fullscale shear wall segments that would typically be used in the construction of a platform framed structure (Fig. 1). The laboratory test procedure was consistent with that used for the preceding research program on wood sheathed CFS framed shear walls [4]. Walls of 610, 1220, 1830 and $2440 \mathrm{~mm}$ in length, all $2440 \mathrm{~mm}$ in height, were constructed of various stud and track thickness, sheathing thickness, screw fastener detailing and framing reinforcement.

\subsection{Related research on steel sheathed CFS framed shear walls}

The nominal shear strength values for steel sheathed CFS framed shear walls available in the AISI S213 Standard [1] for the US and Mexico were derived from a research program conducted by Serrette et al. [15,16]. The test program consisted of 14 test walls of dimensions $610 \times 2440 \mathrm{~mm}$ and $1220 \times 2440 \mathrm{~mm}, 4: 1$ and 2:1 aspect ratios, and constructed of framing members of $0.84 \mathrm{~mm}$ nominal thickness and sheathed with steel sheets of $0.46 \mathrm{~mm}$ and $0.68 \mathrm{~mm}$ nominal thickness. $\mathrm{Yu}$ et al. [17] and Yu \& Chen [18] conducted a suite of shear wall tests with the aim of increasing the wall configurations available in the S213 Standard and to investigate the effects of wall detailing such as framing thickness and sheathing screw fastener size and pattern. Additionally, tests were carried out to verify the results obtained by Serrette et al.. These test walls were constructed of $0.84 \mathrm{~mm}$ and $1.09 \mathrm{~mm}$ thick framing, $0.84 \mathrm{~mm}, 0.76 \mathrm{~mm}$ and $0.68 \mathrm{~mm}$ thick steel sheathing and screw fastener schedules of $50 \mathrm{~mm}, 100 \mathrm{~mm}$, and $150 \mathrm{~mm}$ on-centre. Since some of the design values obtained by Yu et al. were found not to be consistent with those of Serrette et al., Ellis [19] undertook the task of conducting a series of shear wall tests to investigate the reason for the 
discrepancy. It was determined that the difference in measured response was likely a result of the different reversed cyclic protocols used for each test program. Serrette et al. incorporated the sequential phase displacement (SPD) protocol [21,22] into their test program, whilst Yu et al. used a protocol specifically created for light framed structures by the Consortium of Universities for Research in Earthquake Engineering (CUREE) $[23,24]$, which resulted in higher shear resistance.

\section{Shear Wall Test Program}

Although, data from the US based shear wall testing programs [15-19] was available there remained the need to carry out testing of other shear wall configurations to expand on the database required for the development of a Canadian design method. For this reason the scope of testing was defined such that it added to the North American database of information for steel sheathed cold-formed steel framed shear walls. Furthermore, the testing of steel sheathed shear walls under combined lateral and gravity loading had not been attempted prior to the completion of the research described herein.

\subsection{Initial phase shear wall tests}

The test program comprised an initial phase of 54 single-storey steel sheathed shear walls (Configurations 1-18) (Table 1) (Figs. 2-5). The matrix of wall specimens encompassed dimensions (aspect ratios) of $610 \mathrm{~mm} \times 2440 \mathrm{~mm}(4: 1), 1220 \mathrm{~mm} \times 2440 \mathrm{~mm}(2: 1), 1830 \mathrm{~mm} \times$ $2440 \mathrm{~mm}(1.33: 1)$ and $2440 \mathrm{~mm} \times 2440 \mathrm{~mm}(1: 1)$. The framing elements and sheathing panels were of ASTM A653 [25] Grade 230 MPa cold-formed steel. The frames were constructed with tracks (92.1 mm web $\times 38.1 \mathrm{~mm}$ flange) and studs (92.1 mm web $\times 41.3 \mathrm{~mm}$ flange $\times 12.7 \mathrm{~mm}$ 
lip) of thickness $0.84 \mathrm{~mm}$ or $1.09 \mathrm{~mm}$, connected with No. $8 \times 12.7 \mathrm{~mm}$ wafer head self-drilling / self-tapping screws. Chord studs, installed at wall ends, were made from built-up back-to-back studs, connected with two No. 10-16 × $19.1 \mathrm{~mm}$ Hex washer head self-drilling screws at $305 \mathrm{~mm}$ on-centre. The built-up chord members were incorporated in each wall to prevent both flexural and local buckling failure of the end studs. Single field studs were spaced at $610 \mathrm{~mm}$ on-centre along the wall length, except for the $610 \mathrm{~mm}$ long walls, because it is the longest standard spacing typically used in CFS construction. Simpson Strong-Tie S/HD10S hold-down devices [26] were attached to the inside web $75 \mathrm{~mm}$ from each end of the chord studs using No. $14 \times 30 \mathrm{~mm}$ selfdrilling hex washer head screws. Each hold-down device was attached to the test frame by a $22.2 \mathrm{~mm}$ diameter ASTM A193 B7 grade [27] threaded anchor rod. The $0.46 \mathrm{~mm}$ or $0.76 \mathrm{~mm}$ nominal thickness sheathing panels were attached to one face of the wall using No. $8 \times 19 \mathrm{~mm}$ self-drilling - self-tapping pan head screws spaced at $50 \mathrm{~mm}, 75 \mathrm{~mm}, 100 \mathrm{~mm}$ or $150 \mathrm{~mm}$ oncentre over the panel perimeter and at $300 \mathrm{~mm}$ on-centre along the field stud(s). The sheathing panels were available in two sizes; $610 \mathrm{~mm} \times 2440 \mathrm{~mm}$ and $1220 \mathrm{~mm} \times 2440 \mathrm{~mm}$. The $610 \mathrm{~mm}$ and $1220 \mathrm{~mm}$ long walls were sheathed with a single panel (Fig. 2, 3a); whereas, for the $1830 \mathrm{~mm}$ and $2440 \mathrm{~mm}$ long walls two sheathing panels were used with a butt joint on a single field stud

(Fig. 3b, 3c). The perimeter screws were placed at a distance of $9.5 \mathrm{~mm}$ from the edges of each panel. The shear connections from the top and bottom tracks to the test frame were made using 19.1 mm diameter ASTM A325 [28] bolts.

\subsubsection{Modified wall configurations}

The standard wall configurations varied in framing and sheathing thickness, screw fastener schedule and aspect ratio. A limited number of non-standard walls were also constructed to study 
the effect of modifications to their construction on the walls' performance. Wall Configuration 14 was included in the scope of study with the purpose of avoiding the twisting deformations at the ends of the chord studs observed in prior tests of similarly built walls performed by Serrette et al. [15] and Yu et al. [17], and to investigate the use of relatively light framing members (0.84 mm thick) with the thicker sheathing $(0.76 \mathrm{~mm})$. Test $14 \mathrm{M}$-a was constructed with $0.76 \mathrm{~mm} \times 150 \mathrm{~mm}$ $\times 150 \mathrm{~mm}$ triangular gussets plates (230 MPa steel) screw connected (No. $8 \times 19 \mathrm{~mm}$ wafer head self-drilling - self-tapping screws at $38 \mathrm{~mm}$ on-centre) to the four corners of the wall framing to reinforce the ends of the chord stud (Fig. 4a). The sheathing was then installed over top of the frame and the corner plates. In addition, quarter-point bridging members were installed (Fig. 4a) to reduce chord stud twisting deformations. Three bridging channels, $230 \mathrm{MPa}$ grade steel and $1.09 \mathrm{~mm} \times 38.1 \mathrm{~mm} \times 12.7 \mathrm{~mm}$ in size, were placed through the stud web knock-out holes and screw connected with bridging clip-angles. Test 14M-c and 14M-d were also built having quarterpoint bridging reinforcement added to reinforce the studs (Fig. 4b). Test 14M-b was a standard wall, i.e. without reinforcement, that was used to provide a direct comparison with the three modified walls. Similarly, test specimens 9M-c, 5M-c and 6M-c were built using quarter-point bridging members to reduce the twisting deformations of the $1.09 \mathrm{~mm}$ thick chord studs.

Wall Configuration 15 was constructed with the hold-downs raised $610 \mathrm{~mm}$ above the bottom track instead of the usual $75 \mathrm{~mm}$ (Fig. 5a). The upper hold-downs were installed in the standard position. The use of a raised hold-down may be required when the threaded rod is not located properly in the supporting foundation; the raised position allows for a greater distance to align the anchor-rod with the hold-down. As well, raised hold-downs are used to diminish the loss of prestressing force in the anchor-rods as gravity loads are applied to the building. 
Configuration 16 comprised a $2440 \mathrm{~mm} \times 2440 \mathrm{~mm}$ wall constructed with a $1220 \mathrm{~mm} \times 914 \mathrm{~mm}$ window opening (Fig. 5b) for the purpose of evaluating the possibility of coupling the response of the two adjacent high aspect ratio (4:1) shear walls by adding sheathing above and below the opening. The same method of construction as for the other specimens was implemented to build the wall; built-up chord studs were located at the wall ends and single studs were placed at 610 mm on-centre along its length. The inner edge of the two full-height shear wall segments comprised a single stud. Hold-down devices were installed at the four outer corners of the wall. Track elements were used to frame the top and bottom of the opening; clip-angles with screws were used to make the connection to the adjacent studs. Two full-height $610 \mathrm{~mm} \times 2440 \mathrm{~mm}$ steel sheets were placed at each side of the opening, one $1220 \mathrm{~mm} \times 610 \mathrm{~mm}$ sheathing panel was installed above the opening, while a $1220 \mathrm{~mm} \times 914 \mathrm{~mm}$ panel covered the section of the wall underneath the opening. The edges of all sheathing panels had the same fastener spacing as that found along the perimeter of the shear wall.

Wall specimen $17 \mathrm{M}$ was constructed with perimeter frame fasteners placed in a concentrated pattern of $50 \mathrm{~mm}$ spacing on-centre at the four corners, while screws were installed at $300 \mathrm{~mm}$ oncentre elsewhere (Fig. 5c). Since previous tests had been observed to exhibit tension field action the intent was to determine whether this modified screw placement pattern could be relied on to provide similar shear resistance to a wall in which screws were placed at $50 \mathrm{~mm}$ over the entire sheathing panel perimeter (Wall Configuration 2). The remainder of the wall construction was as per the standard configuration.

\subsection{Second phase shear wall tests}


A second phase of shear wall tests was conducted to investigate the influence of combined gravity and lateral loading on the shear walls, and to evaluate the benefit of reinforcing the stud framing with full-size blocking elements. The testing was composed of 14 single-storey steel sheathed shear walls $1220 \mathrm{~mm} \times 2440 \mathrm{~mm}$ (2:1) in size (Configurations B1-B8) (Table 1) (Fig. 6). Construction details of the walls were as described for the initial phase tests except that the chord studs were designed for the anticipated effect of the combined lateral and gravity loading, and blocking was added.

In determining the configurations of the walls the sheathing thickness and screw schedule were first selected to match specific walls from the initial phase of tests. A capacity-based design approach was then used to select the framing components such that the inelastic behaviour would be restricted to the sheathing-to-frame screw connections. The ultimate shear resistances, $\mathrm{S}_{\mathrm{u}}$, determined by Ong-Tone \& Rogers [12] and Balh \& Rogers [13] for the initial phase test specimens were used to calculate the probable compression force on the chord studs based on an assumption of uniform shear flow along the perimeter framing members of a wall (Fig. 7). It was conservatively assumed that a concentrated compression force is applied at the top of the chord studs because of the tension field action that develops in the sheathing. This force was then added to the gravity load exerted on the chord studs to obtain the probable compression force, $\mathrm{C}_{\mathrm{prob}}$. It was assumed that the applied compression forces were eccentric because the steel sheathing was attached to one face of a test wall and to account for accidental misalignment of the gravity load. The moment imposed on the major axis of the built-up studs (out of the plane of the wall) was assumed to result from the summation of the tributary gravity load applied at a distance of $5 \%$ of the stud depth $(0.05 \times 92.1=4.6 \mathrm{~mm})$ and the compressive force in the chord studs due to shearing action on the wall applied at half of the stud depth $(92.1 / 2=46.1 \mathrm{~mm})$. The minor axis of the 
built-up chord studs was considered to resist a moment (in the plane of the wall) equal to the gravity load applied at $5 \%$ of the built-up flange dimension $(0.05 \times(2 \times 41.3))=4.1 \mathrm{~mm})$, since the chords were constructed of two studs. All eccentricities were defined with respect to the centroid of the built-up chord studs. Note, these assumptions for eccentrically applied axial loads on the chord studs are consistent with those used for the design of the double-storey dynamic shear wall test specimens by Shamim et al. [29].

The chord studs were treated as beam-column elements with combined axial compression and flexural loads, and as such, were designed using the interaction equations for stability and strength specified in CSA S136 [2]. The result of this design procedure was that thicker chord-studs of 1.37 mm were required for some of the test walls compared to those used in the construction of the initial phase walls (Table 1). The blocking members were chosen to be the same size and thickness as the track members for simplicity and were screw connected to the studs at quarter-points over the wall height (Fig. 8).

\subsection{Fabrication, setup and instrumentation}

All shear wall specimens were assembled in the Jamieson Structures Laboratory at McGill University, with the appropriate holes pre-drilled in the top and bottom tracks to accept the required shear and hold-down connections. The built-up chord members were first connected and then were installed with hold-downs. The track and stud steel framing members were connected with No. 8 wafer head screws, and reinforcement was added when specified. This was followed by installation of the steel sheathing, connected with No. 8 pan head screws. Each wall was then placed into the reaction frame which had been specifically constructed for the testing of CFS walls (Fig. 9). It consisted of a $250 \mathrm{kN}$ capacity actuator having a displacement range of $\pm 125 \mathrm{~mm}$. Lateral bracing 
at the wall top ensured that only in-plane deformation of the wall specimen took place. Once a specimen was placed in the test frame and aligned, shear anchors and hold-downs were tightened following the manufacturer's instructions. Load cells were placed on the hold-down threaded rods. LVDTs and string potentiometers were then installed to record the in-plane deformations of the test wall, including; slip, uplift and top of wall displacement. The measurement instruments were connected to Vishay Model 5100B scanners which were used to record data using the Vishay System 5000 StrainSmart software.

The test frame was modified for the second phase of testing (Configurations B1 to B8) to allow for the application of a $12.5 \mathrm{kN}$ gravity load $(10.25 \mathrm{kN} / \mathrm{m})$ to the shear walls along with lateral displacements. A loading system which consisted of a load box and roller assembly was designed and installed (Fig. 10). The rollers and springs allowed the gravity box to move vertically with the test wall but restricted longitudinal movement in and out of the plane of the wall. This gravity loading device was also used for the shake table dynamic testing of CFS framed shear walls [29]. The installation of measurement instruments was as described for the initial phase of tests.

\subsection{Shear wall displacement based loading protocols}

The shear walls were tested using displacement based protocols while measuring the resistance and relevant displacements. All monotonic tests were carried out from the zero lateral force position using a unidirectional in-plane displacement rate of $2.5 \mathrm{~mm} / \mathrm{min}$. Displacement loading continued until the measured force on the specimen degraded significantly or until a displacement of $100 \mathrm{~mm}$ was reached, which corresponds to a storey drift of $4 \%$. The monotonic test results were also required to determine the displacement amplitudes for the reversed cyclic protocols. 
The CUREE protocol for ordinary ground motions [23, 24], initially developed with the notion that multiple earthquakes may occur during the lifetime of the structure, was chosen for the reversed cyclic shear wall tests. It subjects components to representative ordinary ground motions (not near-fault) whose probability of exceedance in 50 years is $10 \%$. The monotonic deformation capacity, $\Delta_{\mathrm{m}}$, (maximum inelastic response) is a post-peak deflection defined as the position at which the wall resistance is reduced to $80 \%$ of the maximum (peak) resistance. A reference deformation is defined as $0.6 \Delta_{\mathrm{m}}$; the displacement amplitudes of the protocol are then obtained as multiples of this reference deformation. The initial phase tests were run at $0.5 \mathrm{~Hz}$ starting at the zero lateral force position, while the second phase tests were set at $0.1 \mathrm{~Hz}$ to allow for the operation of the rolling gravity weight. Note, for both the monotonic and reversed cyclic tests of the second phase specimens the gravity load was first applied followed by application of the respective lateral displacement loading protocol.

\subsection{Ancillary testing of materials}

Ancillary tests were carried out to establish the material properties of the steel frame and sheathing components. Material properties for the studs, tracks and sheathing were obtained following ASTM A370 [30] (Table 2). Note, the studs and tracks of a specific thickness were obtained from the same coil of steel and the steels used for the first and second phases of tests were sourced separately. The resulting mechanical properties of all test materials satisfied the minimum requirements of the CSA S136 Specification [2] of tensile strength to yield stress ratio $\left(\mathrm{F}_{\mathrm{u}} / \mathrm{F}_{\mathrm{y}}\right)$ greater than 1.08 and $10 \%$ minimum elongation over a $50 \mathrm{~mm}$ gauge length. 


\subsection{Observed shear wall performance}

All shear walls exhibited elastic shear buckling of the sheathing panels at low load levels. As the lateral displacement increased this was followed by the development of a tension field in each panel, as illustrated in Fig. 11. Note, Fig. 11a shows the post-test state of a wall subjected to reversed cyclic loading, and hence the two opposing tension fields. The walls $1830 \mathrm{~mm}$ and 2440 $\mathrm{mm}$ long independently developed a tension field in each of the two full-height sheathing panels (Fig. 11b). The ultimate shear resistance of the initial phase walls, including those modified with additional bridging reinforcement, was directly related to the failure of the sheathing-to-framing connections (Fig. 12) and in many cases the twisting of the chord studs (Fig. 13). The sheathing connections typically failed by bearing distortion of the sheathing (Fig. 12a) which in some cases developed into a plug shear type failure path at the edge of the panel, fastener pull-through (Fig. 12b) which was more common in the walls with $0.46 \mathrm{~mm}$ thick sheathing and fastener pull-out (Fig. 12c) which was normally observed in the walls with $0.84 \mathrm{~mm}$ thick framing members. Wall yielding took place in a progressive manner, characterised by unzipping of the sheathing connections typically around the wall corners where the tension field forces were highest. The sheathing was often detached from the frame at these locations by the end of the loading protocol. The connection failure modes were dependant on the wall configuration, more specifically, the relative difference in material properties (thickness and strength) between the sheathing and framing. Walls with sheathing panels much thinner than the framing typically experienced higher occurrences of fastener pull-through failures. Test walls with sheathing of close thickness to the framing typically experienced screw pull-out. This was especially the case of test $7 \mathrm{M}-\mathrm{a}$, constructed with the lighter $0.84 \mathrm{~mm}$ thick framing and $0.76 \mathrm{~mm}$ sheathing. These types of sheathing-to-framing connection failures were expected, and are consistent with the seismic design 
philosophy applied to wood sheathed shear walls in AISI S213 [1,6], in which the energy dissipating element in the lateral load path is specified as the sheathing connections. However, in walls with $0.76 \mathrm{~mm}$ thick sheathing and a closely spaced fastener pattern substantial twisting deformation of the chord studs (Fig. 13) was recorded. The denser connector spacing coupled with the increased bearing resistance of the thicker sheathing allowed the screw connections to resist higher lateral loads and for larger tension field forces to develop. This chord stud deformation was attributed to the concentrated tension field (Fig. 13a) which resulted in the application of a horizontal component of force on the chord studs and a subsequent torsional moment. Figure 13b illustrates the damage that can occur to these stud members when loaded in this manner, which in the case of inelastic seismic response could lead to failure of the gravity load carrying system postearthquake.

The walls with an aspect ratio of 4:1 (610 mm long) showed a greater flexural in-plane response compared with all longer walls with the associated connection and chord stud damage, and typically were able to reach a displacement approaching the $4 \%$ drift limit used in testing.

Due to this undesired damage to the chord studs of the initial phase walls, test specimens $14 \mathrm{M}-\mathrm{a}$, 14M-c, 14M-d, 9M-c, 5M-c and 6M-c were constructed with quarter point bridging members to resist the torsional moments on the chord members. The extent of chord twisting was reduced. Nonetheless, the walls with lighter chord studs (14M Wall Configuration) had insufficient axial resistance, especially for the $50 \mathrm{~mm}$ sheathing screw spacing, and thus suffered from chord stud failure. Specimen 14M-a, constructed with additional corner plates to reinforce the chord studs, did not provide for better performance compared with walls $14 \mathrm{M}$-c and $14 \mathrm{M}$-d due to the inadequate chord stud size. The general failure of the thicker framed walls with reinforcement (9M-c, 5M-c and 6M-c) was attributed to the sheathing connections. However, due to the 
slenderness of the bridging channels their failure by lateral torsional buckling caused by the end moments applied at the chord stud-to-bridging intersection (Fig. 14) was identified. Based on this observation a recommendation was made to carry out the second phase of tests on walls with blocking elements of greater flexural stiffness and resistance as well as with studs that had been selected using a capacity design approach.

Wall Configuration 15 with the raised hold-downs demonstrated the same sheathing connection failure modes and chord stud twisting as observed for all specimens from matching Wall Configuration 5. As such, it was concluded that the position of the hold-downs in this case did not affect the overall performance of the shear wall under lateral loading.

Test wall 16M-a, with the window opening and additional sheathing panels above and below the opening, experienced elastic shear buckling of the $610 \mathrm{~mm} \times 2440 \mathrm{~mm}$ sheathing panels on both sides of the window opening, along with the typical tension field development and sheathing connection failures. However, the governing failure was that of the window framing, which limited the ability of the two high aspect ratio shear wall segments to be coupled by means of the additional sheathing above and below the opening. Pull-out of the screws for the clip-angles used to connect the tracks to the field studs caused warping distortion of the studs. The studs also failed by localized bending due to the lateral load from the window frame tracks. It was concluded that the fixity of the window framing was inadequate in terms of shear transfer; thus, a more robust construction and design procedure is needed to account for the transfer of shear forces around openings in shear walls if a coupled shear wall action is desired.

Wall Configuration 17, which contained a reduced number of sheathing connections away from the corners, i.e. the tension field anchor locations, compared with all specimens from Wall Configuration 2, exhibited similar shear buckling, tension field development and sheathing 
connection failure, but was not able to reach the same load levels, as further discussed in Section 2.6. This indicates that although a tension field develops in the sheathing panels all of the fasteners along the panel perimeter contribute to the shear resistance of the wall, and as such the ultimate shear resistance of a steel sheathed wall can be attributed to the combination of shear buckling and tension field actions.

The second phase of testing comprised walls in which both lateral and gravity loads were applied; for this reason the chord studs were placed under higher force demand compared with the previous tests. The majority of observed failure modes were similar to the conventional steel sheathed shear walls; elastic shear buckling of the panels was first observed (Fig. 15a), followed by the development of a tension field (Fig. 15a), which led to the final failure of the sheathing connections (Fig. 15b,c). The chord studs, however, did not suffer local and/or overall buckling failures due to excessive axial forces nor were the blocking members damaged. In a few cases, local buckling of the chord studs' flange-lip elements was observed after the ultimate shear resistance had been reached. This occurred due to weak axis bending of the chord studs which acted as beams members to transfer the shear force after the sheathing had become detached from the framing (Fig. 15c).

Although no overall twisting damage occurred to the chord studs in the reinforced shear walls, due to the open cross-section and the large tension field forces, especially with walls having a $50 \mathrm{~mm}$ screw spacing and $0.76 \mathrm{~mm}$ thick sheathing, some distortion of the flange-lip component was observed (Fig. 15b). Given the ability of the walls, and specifically the chord studs, to carry the combined gravity and shear loads this level of damage during inelastic loading was not considered to be detrimental to the axial load carrying resistance. Uplift deformations of the track elements were observed (15c), but were of a minor nature, and this could be improved with the use of plate washers at shear anchor locations. The blocking reinforcement, which resulted in a reduced un- 
braced length and increased twisting restraint for the studs, combined with a proper capacity based design approach accounting for possible eccentric axial forces was effective in preventing chord stud failure.

\subsection{Measured wall properties}

Properties measured from each of the shear wall configurations are provided in Table 3 (monotonic loading protocol) and Tables 4 and 5 (reserved cyclic loading protocol). Average values were tabulated for shear wall specimens within the same configuration since their performances were similar, except if modifications as described in Section 2.1.1 were made. Data includes the ultimate shear resistance, $\mathrm{S}_{\mathrm{u}}$, and the lateral displacement, $\Delta$, and rotation, $\theta$, at $0.4 \mathrm{~S}_{\mathrm{u}}, \mathrm{S}_{\mathrm{u}}$ and $0.8 \mathrm{~S}_{\mathrm{u}}$ (postpeak) as well as the dissipated energy. The definition of all terms, shown on representative resistance vs. displacement curves, can be seen in Figs. 16 and 17. In the case of the reversed cyclic tests a backbone curve in both the positive and negative displacement quadrant was first identified to envelop the measured displacement cycles; from this, measured properties were determined including the dissipated energy which was defined as the area beneath the backbone curve.

In general, the use of closely spaced sheathing panel fasteners and thicker panels leads to a higher shear resistance. However, this is only true if the stud members are designed to carry the additional force, as demonstrated by the Configuration 7, 10 and 14 walls for which the $0.84 \mathrm{~mm}$ thick studs did not allow for an increase in shear resistance.

Initial phase walls with the same configuration but different lengths could also be compared to identify the influence of aspect ratio. The monotonic results for Configurations 8 (610 mm - 4:1 ratio $-12.9 \mathrm{kN} / \mathrm{m}), 5(1220 \mathrm{~mm}-2: 1$ ratio $-13.8 \mathrm{kN} / \mathrm{m}), 12(1830 \mathrm{~mm}-1.5: 1$ ratio $-14.4 \mathrm{kN} / \mathrm{m})$ 
and 11 (2440 $\mathrm{mm}$ - 1:1 ratio $-15.3 \mathrm{kNm}$ ) showed that the resistance (force per unit length) increased with the wall length. The same result was obtained for Configurations 9 (610 mm - 4:1 ratio $-14.7 \mathrm{kN} / \mathrm{m}), 6(1220 \mathrm{~mm}-2: 1$ ratio $-16.7 \mathrm{kN} / \mathrm{m})$ and $13(1830 \mathrm{~mm}-1.5: 1$ ratio - 18.5 $\mathrm{kN} / \mathrm{m}$ ). This was not expected, because for similar wood sheathed walls it was shown that with aspect ratios between 2:1 and 1:1 the shear resistance per unit length remains near constant [5]. This result can be explained because the shear resistance of these un-blocked steel sheathed walls was related to the twisting of the chord studs as well as the sheathing connections, whereas for the wood sheathed walls the behaviour was solely controlled by the sheathing connections. Although tests were not carried out on blocked walls of various lengths, it is likely that the shear resistance per unit length would be similar for the walls if the chord studs were adequately protected from damage, except those with an aspect ratio greater than 2:1,.

Wall Configuration 16, which contained a window opening and two 4:1 full-height shear wall segments, can be compared with Wall Configuration 8, a single 4:1 aspect ratio shear wall. The shear resistance per unit length for the single shear wall was $12.9 \mathrm{kN} / \mathrm{m}$, while a lower value was obtained for the $2.44 \mathrm{~m}$ long wall; $9.9 \mathrm{kN} / \mathrm{m}$. However, if the calculation were carried out using the length of the full-height shear wall segments alone, the resistance would be $19.8 \mathrm{kN} / \mathrm{m}$. Thus, a benefit in terms of shear resistance was obtained by installing sheathing above and below the window opening. However, as noted in Section 2.5, the response of specimen 16M-a could have been improved with appropriate design of the shear transfer around the window opening.

The construction of Wall Configuration 15 with raised hold-downs did not affect the shear resistance compared to the same wall (Configuration 5) which had hold-downs placed in the standard position. A shear resistance of $13.8 \mathrm{kN} / \mathrm{m}$ was obtained in both cases. 
The sheathing screw spacing for Wall Configuration 2 was selected as $50 \mathrm{~mm}$ on-centre. Wall 17 was built with this same screw spacing, but only in the tension field anchor zones. The decreased resistance of Wall 17, $7.75 \mathrm{kN} / \mathrm{m} v s .10 .0 \mathrm{kN} / \mathrm{m}$, indicates that the shear resistance is a function of both the shear buckling resistance and tension field action in the sheathing panels.

Wall Configuration 14 was composed of a standard wall, and two modified wall types. The addition of channel bridging elements allowed for a minor increase in shear resistance $(14.8 \mathrm{kN} / \mathrm{m}$ vs. $13.5 \mathrm{kN} / \mathrm{m}$ ). Note wall $14 \mathrm{M}-\mathrm{c}$, constructed with bridging, was only able to reach a resistance of $13.7 \mathrm{kN} / \mathrm{m}$ due to stud failure. Wall $14 \mathrm{M}$-a, built with bridging and corner reinforcement, attained a slightly higher resistance of $15.2 \mathrm{kN} / \mathrm{m}$, however soon thereafter the corner plates became disconnected and the resistance dropped rapidly resulting in a low ductility. The limited change in performance for these walls is attributed to the chord studs being of inadequate size to carry the shear induced forces.

A comparison of the shear resistance vs. deformation of similarly configured blocked, bridged and un-blocked shear walls subjected to the monotonic loading protocol is provided in Fig. 18. The normalized shear resistance for a selection of the second phase blocked walls was first determined, where the resistance for each wall was normalized with respect to the ultimate value measured during testing. For illustrative purposes, a similarly constructed (screw pattern, sheathing thickness and framing) un-blocked initial phase wall was then normalized to the ultimate shear resistance of the blocked wall. Thus a graphical comparison of un-blocked walls with their blocked counterparts is shown; $1 \mathrm{M}-\mathrm{a}$ vs. B6-M, 2M-a vs. B2-M, 4M-a vs. B4-M and 5M-a vs. B3-M. This graphical comparison was also carried out for the reversed cyclically tested walls B3-R and 5C-b (Fig. 19). Note, a direct comparison of the walls with $0.76 \mathrm{~mm}$ thick sheathing and screws placed at $50 \mathrm{~mm}$ on-centre (Wall Configuration 6 vs. B1) could not be made because the chord stud thickness was 
increased from $1.09 \mathrm{~mm}$ to $1.37 \mathrm{~mm}$ due to the requirements of the capacity based design calculations used in the second phase of testing. Even though the second phase walls were subjected to a gravity load the increase in shear resistance is substantial due to the improved performance of the chord studs, which for the blocked walls did not suffer from torsional failure. The increase in shear resistance was not due to the presence of a gravity load knowing that the final failure of the blocked walls was not related to the tension end of the wall, e.g. hold-down failure. However, since the response of the blocked walls was largely dependent on the sheathing connections, the ductility (lateral displacement) of the walls was reduced. The torsional damage to the chord studs in the un-blocked walls led to greater ductility because of the large member distortions that occurred. Conversely, this increase in ductility comes with a significant risk of failure for the gravity load carrying members. Figure 18 also includes the resistance vs. displacement response of test wall 5M-c, for which additional bridging channel elements were added. The shear resistance was augmented compared to wall 5M-a, although, not to the same level as the comparable blocked wall B3-M. The ductility of the bridged wall did not decrease compared with specimen 5M-a due to the large distortion of the bridging and final torsional damage to the chord studs. In terms of shear resistance and protection of the gravity load carrying framing the use of blocked studs and a capacity based design approach is beneficial.

\section{Comparison of general behaviour with wood sheathed CFS framed shear walls}

A brief qualitative comparison of the general behaviour of wood versus steel sheathed CFS framed panels is provided in this section. The previously tested wood sheathed CFS framed shear walls $[4,5]$ generally responded to lateral loading in the same fashion as the steel sheathed walls described herein. That is, the overall shape of the shear resistance vs. rotation (lateral deflection) 
curves (monotonic \& reversed cyclic) for the two differently sheathed shear walls was similar and the behaviour was largely influenced by the resistance, stiffness and ductility of the sheathing-toframing connections. However, the commonly available structural wood sheathing panels, whether plywood or oriented strand board, are of greater shear stiffness than the steel sheathing panels used for testing and thus did not develop elastic shear buckles or tension field action under lateral loading. The forces on the wood sheathing-to-frame connections, and recorded damage, were typically distributed around the perimeter of the sheathing panels in a relatively uniform pattern. In the steel sheathed walls, due to the elastic shear buckling at low loads and the subsequent tension field development in the sheathing, the connections at the corners of the panels were subjected to much higher forces than those located elsewhere along the perimeter of the panel. This concentrated force demand resulted in higher damage at the corner connections compared with the other sheathing connections and lower overall ductility of the steel sheathed shear walls. Furthermore, the wood sheathed shear walls did not exhibit damage due to twisting of the chord studs. This was likely due to two aspects; 1 ) the wood sheathing provided torsional support to the studs due to its greater thickness $(9.5,11 \& 12.5 \mathrm{~mm}$ vs. $0.46 \& 0.76 \mathrm{~mm}$ for the steel sheathing), and 2) because a tension field force did not develop in the sheathing panels, and thus a large eccentrically located concentrated horizontal force component in the plane of the panel was not applied to the studs. Lastly, the ultimate shear resistance values measured for the steel sheathed walls were lower than those obtained for the wood sheathed walls with the same fastener patterns and framing thickness; however, this situation could likely be improved by the use of steel panels of greater thickness than those tested. 


\section{Conclusions}

A program of displacement based loading tests, 68 specimens in total, was carried out on singlestorey steel sheathed CFS framed shear walls of various configurations to investigate their performance and to establish a comprehensive database of information for the development of a subsequent design method [20]. The walls differed in framing thickness, sheathing thickness, screw fastener detailing, aspect ratio and framing reinforcement. The initial phase of tests included lateral loading protocols, while the second phase involved shear walls subjected to combined lateral and gravity loading. In general, the use of closely spaced sheathing panel fasteners and thicker panels leads to a higher shear resistance if the stud members are designed to carry the additional force. When the framing elements were not blocked tension field forces in the sheathing resulted in significant damage to the chord studs. The use of blocked studs and a capacity based design approach allowed for an increased shear resistance and protection of the gravity load carrying framing members. Although a distinct tension field develops in the sheathing under lateral loading, a component of the shear resistance is also dependent on the shear buckling response of the panel. The position of the hold-down devices did not affect the lateral load carrying resistance of the walls. The influence of aspect ratio on shear resistance could not be specifically examined because the performance of the walls was affected by the damage caused to the chord studs. The testing of blocked walls was limited to specimens of $1200 \mathrm{~mm} \times 2440 \mathrm{~mm}$ in size; testing of other length blocked shear walls is recommended to better understand the change in response with aspect ratio. Sheathed elements of a wall above and below openings may lead to better shear performance of the overall lateral load carrying system; however, proper design for shear transfer around openings is required. 


\section{Acknowledgements}

The authors would like to acknowledge the support provided by the Natural Sciences and Engineering Research Council of Canada (NSERC), the Canadian Sheet Steel Building Institute (CSSBI) and the American Iron and Steel Institute (AISI). Materials for construction of the test specimens were provided by Simpson Strong-Tie Co. Inc., ITW Buildex and Grabber Construction

Products. Assistance with the procurement of steel framing was provided by Bailey Metal Products Limited. 


\section{References}

[1] American Iron and Steel Institute (AISI). North American standard for cold-formed steel framing - lateral design. AISI S213. Washington, USA. 2007.

[2] Canadian Standards Association (CSA). North American specification for the design of coldformed steel structural members. CSA S136. Mississauga, Canada. 2007.

[3] National Research Council of Canada (NRCC). National Building Code of Canada. $13^{\text {th }}$ Edition. Ottawa, Canada. 2010.

[4] Branston, AE, Chen, CY, Boudreault, FA, Rogers, CA. Testing of light-gauge steel-frame wood structural panel shear walls. Canadian Journal of Civil Engineering, 33(5), 561-572. 2006.

[5] Chen CY, Boudreault FA, Branston AE, Rogers CA. Behaviour of light-gauge steel-frame wood structural panel shear walls. Canadian Journal of Civil Engineering, 33(5), 573-587. 2006.

[6] Branston AE, Boudreault FA, Chen CY, Rogers CA. Light-gauge steel-frame - wood structural panel shear wall design method. Canadian Journal of Civil Engineering, 33(7), 872-889. 2006.

[7] Boudreault FA, Blais C, Rogers CA. Seismic force modification factors for light-gauge steelframe - wood structural panel shear walls. Canadian Journal of Civil Engineering, 34(1), 56-65. 2007.

[8] Al-Kharat M, Rogers CA. Inelastic performance of cold-formed steel strap braced walls. Journal of Constructional Steel Research, 63(4), 460-474. 2007.

[9] Al-Kharat M, Rogers CA. Inelastic performance of screw connected cold-formed steel strap braced walls. Canadian Journal of Civil Engineering, 35(1), 11-26. 2008.

[10] Velchev K, Comeau G, Balh N, Rogers CA. Evaluation of the AISI S213 seismic design procedures through testing of strap braced cold-formed steel walls. Thin-Walled Structures, 48(10-11), 846-856. 2010.

[11] Comeau G, Velchev K, Rogers CA. Development of seismic force modification factors for cold-formed steel strap braced walls. Canadian Journal of Civil Engineering, 37(2), 236249. 2010. 
[12] Ong-Tone C, Rogers CA. Tests and evaluation of cold-formed steel frame /steel sheathed shear walls, Research Report. Montreal, Canada: Dept. of Civil Engineering \& Applied Mechanics, McGill University; 2009.

[13] Balh N, Rogers CA. Development of seismic design provisions for steel sheathed shear walls, Research Report. Montreal, Canada: Dept. of Civil Engineering \& Applied Mechanics, McGill University; 2010.

[14] DaBreo J, Rogers CA. Steel sheathed shear walls subjected to combined lateral and gravity loads, Research Report. Montreal, Canada: Dept. of Civil Engineering \& Applied Mechanics, McGill University; 2012.

[15] Serrette RL, Nguyen H, Hall G. Shear wall values for light weight steel framing. Report No. LGSRG-3-96. Santa Clara, USA; Dept. of Civil Engineering, Santa Clara University; 1996.

[16] Serrette RL, Encalada J, Matchen B, Nguyen H, Williams A. Additional shear wall values for light weight steel framing, Report No. LGSRG-1-97. Santa Clara, USA; Dept. of Civil Engineering, Santa Clara University; 1997.

[17] Yu C, Vora H, Dainard T, Tucker J, Veetvkuri P. Steel sheet sheathing options for coldformed steel framed shear wall assemblies providing shear resistance, Report No. UNTG76234. Denton, USA; Dept. of Engineering Technology, University of North Texas; 2007.

[18] Yu C, Chen Y. Steel sheet sheathing options for cold-formed steel framed shear wall assemblies providing shear resistance - Phase 2, Report No. UNT-G70752. Denton, USA; Dept. of Engineering Technology, University of North Texas; 2009.

[19] Ellis J. Shear resistance of cold-formed steel framed shear wall assemblies using CUREE test protocol. Simpson Strong-Tie Co. Inc, Anaheim, USA. 2007.

[20] Balh N, DaBreo J, Ong-Tone C, El-Saloussy K, Yu C, Rogers CA. Design of steel sheathed cold-formed steel framed shear walls. Thin-Walled Structures, under review, TWST-D-1300328.

[21] Porter ML. Sequential phased displacement (SPD) procedure for TCCMAR testing. Proceedings of the Third Meeting of the Joint Technical Coordinating Committee on Masonry Research, U.S. - Japan Coordinated Earthquake Research Program, Tomamu, Japan. The Masonry Society, Boulder, USA. 1987.

[22] Structural Engineers Association of Southern California (SEAOSC). Standard method of cyclic (reversed) load test for shear resistance of framed walls for buildings. Whittier, 
USA. 1997.

[23] Krawinkler H, Parisi F, Ibarra L, Ayoub A, Medina R. Development of a testing protocol for woodframe structures. Report W-02 covering Task 1.3.2, CUREE/Caltech Woodframe Project. Consortium of Universities for Research in Earthquake Engineering (CUREE). Richmond, USA. 2000.

[24] American Society for Testing and Materials (ASTM). Standard test methods for cyclic (reversed) load test for shear resistance of vertical elements of the lateral force resisting systems for buildings. ASTM E2126. West Conshohocken, USA. 2011.

[25] American Society for Testing and Materials (ASTM). Standard specification for steel sheet, zinc-coated (galvanized) or zinc-iron alloy-coated (galvannealed) by hot-dip prcess. ASTM A653, West Conshohocken, USA. 2008.

[26] Simpson Strong-Tie Co.. Light Gauge Steel Construction Connectors. Dublin, USA. 2008.

[27] American Society for Testing and Materials (ASTM). Standard specification for alloy-steel and stainless steel bolting materials for high temperature or high pressure service and other special purpose applications. ASTM A193, West Conshohocken, USA. 2008.

[28] American Society for Testing and Materials (ASTM). Standard specification for structural bolts, steel, heat treated 120/105 ksi minimum tensile strength. ASTM A325, West Conshohocken, USA. 2010.

[29] Shamim I, DaBreo J, Rogers CA. Dynamic testing of single- and double-story steel sheathed cold-formed steel framed shear walls. Journal of Structural Engineering ASCE, 139(5), 807817. 2013.

[30] American Society for Testing and Materials (ASTM). Standard test methods and definitions for mechanical testing of steel products. ASTM A370, West Conshohocken, USA. 2009. 
Table 1: Matrix of shear wall test specimens (nominal dimensions)

\begin{tabular}{|c|c|c|c|c|c|c|}
\hline Configuration & $\begin{array}{c}\text { Number of } \\
\text { Tests \& } \\
\text { Protocol }^{4}\end{array}$ & $\begin{array}{c}\text { Wall } \\
\text { Length } \\
(\mathrm{mm})\end{array}$ & $\begin{array}{c}\text { Wall } \\
\text { Height } \\
(\mathrm{mm})\end{array}$ & $\begin{array}{c}\text { Framing } \\
\text { Thickness } \\
\text { (mm) }\end{array}$ & $\begin{array}{c}\text { Sheathing } \\
\text { Thickness } \\
\text { (mm) }\end{array}$ & $\begin{array}{c}\text { Fastener }^{5} \\
\text { Schedule } \\
(\mathrm{mm})\end{array}$ \\
\hline $1^{1}$ & $3 \mathrm{M} \& 2 \mathrm{C}$ & 1220 & 2440 & 1.09 & 0.46 & $150 / 300$ \\
\hline $2^{1}$ & $2 \mathrm{M} \& 2 \mathrm{C}$ & 1220 & 2440 & 1.09 & 0.46 & $50 / 300$ \\
\hline $3^{1}$ & $2 \mathrm{M} \& 3 \mathrm{C}$ & 1220 & 2440 & 0.84 & 0.46 & $150 / 300$ \\
\hline $4^{2}$ & $2 \mathrm{M} \& 2 \mathrm{C}$ & 1220 & 2440 & 1.09 & 0.76 & $150 / 300$ \\
\hline $5^{2}$ & $3 \mathrm{M}^{10} \& 2 \mathrm{C}$ & 1220 & 2440 & 1.09 & 0.76 & $100 / 300$ \\
\hline $6^{2}$ & $3 \mathrm{M}^{10} \& 2 \mathrm{C}$ & 1220 & 2440 & 1.09 & 0.76 & $50 / 300$ \\
\hline $7^{2}$ & $1 \mathrm{M}$ & 1220 & 2440 & 0.84 & 0.76 & $100 / 300$ \\
\hline $8^{1}$ & $2 \mathrm{M} \& 2 \mathrm{C}$ & 610 & 2440 & 1.09 & 0.76 & 100 \\
\hline $9^{1}$ & $3 \mathrm{M}^{10} \& 2 \mathrm{C}$ & 610 & 2440 & 1.09 & 0.76 & 50 \\
\hline $10^{1}$ & $1 \mathrm{M}$ & 610 & 2440 & 0.84 & 0.76 & 100 \\
\hline $11^{1}$ & $2 \mathrm{M} \& 2 \mathrm{C}$ & 2440 & 2440 & 1.09 & 0.76 & $100 / 300$ \\
\hline $12^{2}$ & $1 \mathrm{M}$ & 1830 & 2440 & 1.09 & 0.76 & $100 / 300$ \\
\hline $13^{2}$ & $1 \mathrm{M}$ & 1830 & 2440 & 1.09 & 0.76 & $50 / 300$ \\
\hline $14^{2}$ & $4 \mathrm{M}^{9}$ & 1220 & 2440 & 0.84 & 0.76 & $50 / 300$ \\
\hline $15^{2}$ & $1 M^{7}$ & 1220 & 2440 & 1.09 & 0.76 & $100 / 300$ \\
\hline $16^{2}$ & $1 \mathrm{M}^{8}$ & 2440 & 2440 & 1.09 & 0.76 & $100 / 300$ \\
\hline $17^{1}$ & $2 \mathrm{M}^{6}$ & 1220 & 2440 & 1.09 & 0.46 & $50-300 / 300$ \\
\hline $18^{1}$ & $1 \mathrm{M}$ & 1220 & 2440 & 1.09 & 0.46 & 75/300 \\
\hline $\mathrm{B} 1^{3}$ & $1 \mathrm{M} \& 1 \mathrm{R}$ & 1220 & 2440 & 1.37 & 0.76 & $50 / 300$ \\
\hline $\mathrm{B} 2^{3}$ & $1 \mathrm{M} \& 1 \mathrm{R}$ & 1220 & 2440 & 1.09 & 0.46 & $50 / 300$ \\
\hline $\mathrm{B}^{3}$ & $1 \mathrm{M} \& 1 \mathrm{R}$ & 1220 & 2440 & 1.09 & 0.76 & $100 / 300$ \\
\hline $\mathrm{B} 4^{3}$ & $1 \mathrm{M} \& 1 \mathrm{R}$ & 1220 & 2440 & 1.09 & 0.76 & $150 / 300$ \\
\hline $\mathrm{B} 5^{3}$ & $1 \mathrm{M} \& 1 \mathrm{R}$ & 1220 & 2440 & 1.09 & 0.46 & $100 / 300$ \\
\hline $\mathrm{B} 6^{3}$ & $1 \mathrm{M} \& 1 \mathrm{R}$ & 1220 & 2440 & 1.09 & 0.46 & $150 / 300$ \\
\hline $\mathrm{B} 7^{3}$ & $1 \mathrm{M}$ & 1220 & 2440 & 1.37 & 0.76 & $75 / 300$ \\
\hline$B 8^{3}$ & $1 \mathrm{M}$ & 1220 & 2440 & 1.37 & 0.46 & $75 / 300$ \\
\hline
\end{tabular}

${ }^{1}$ Balh \& Rogers [13]

${ }^{2}$ Ong-Tone \& Rogers [12]

${ }^{3}$ DaBreo \& Rogers [14]; frames reinforced with quarter-point blocking (same size as track members)

${ }^{4}$ M-Monotonic, C\&R-CUREE reserved cyclic protocol for ordinary ground motions [23,24].

${ }^{5}$ Fastener schedule, e.g. 75/305 refers to the spacing in mm between the sheathing to framing screws on the panel perimeter and along the intermediate studs (field spacing), respectively.

${ }^{6}$ Varying perimeter fastener schedule (see Fig. 5c)

${ }^{7}$ Raised hold-downs (see Fig. 5a)

${ }^{8}$ Wall with window openings (see Fig. 5b)

${ }^{9}$ Various reinforcement schemes (see Fig. 4)

${ }^{10}$ Addition of bridging reinforcement to Tests 5M-c, 6M-c, 9M-c 
Table 2: Measured material properties of CFS components

\begin{tabular}{ccccccc}
\hline Specimen & Member & $\begin{array}{c}\text { Base Metal } \\
\text { Thickness } \\
(\mathbf{m m})\end{array}$ & $\begin{array}{c}\mathbf{F}_{\mathbf{y}} \\
\mathbf{( M P a )}\end{array}$ & $\begin{array}{c}\mathbf{F}_{\mathbf{u}} \\
\mathbf{( M P a})\end{array}$ & $\mathbf{F u}_{\mathbf{u}} / \mathbf{F} \mathbf{y}$ & $\begin{array}{c}\text { \% Elong. } \\
\mathbf{5 0} \mathbf{~ m m} \text { Gauge }\end{array}$ \\
\hline $0.84 \mathrm{~mm}, 230 \mathrm{MPa}^{1}$ & Stud/track & 0.87 & 342 & 391 & 1.14 & 31.0 \\
$1.09 \mathrm{~mm}, 230 \mathrm{MPa}^{1}$ & Stud/track & 1.14 & 346 & 496 & 1.43 & 31.3 \\
$0.46 \mathrm{~mm}, 230 \mathrm{MPa}^{1}$ & Sheathing & 0.46 & 300 & 395 & 1.32 & 26.2 \\
$0.76 \mathrm{~mm}, 230 \mathrm{MPa}^{1}$ & Sheathing & 0.76 & 284 & 373 & 1.32 & 34.9 \\
$1.09 \mathrm{~mm}, 230 \mathrm{MPa}^{2}$ & Stud/track & 1.12 & 301 & 347 & 1.16 & 45.3 \\
$1.37 \mathrm{~mm}, 340 \mathrm{MPa}^{2}$ & Stud/track & 1.37 & 388 & 529 & 1.36 & 34.6 \\
$0.46 \mathrm{~mm}, 230 \mathrm{MPa}^{2}$ & Sheathing & 0.45 & 266 & 358 & 1.35 & 24.8 \\
$0.76 \mathrm{~mm}, 230 \mathrm{MPa}^{2}$ & Sheathing & 0.79 & 337 & 377 & 1.12 & 31.9 \\
\hline
\end{tabular}

${ }^{1}$ Balh \& Rogers [13] \& Ong-Tone \& Rogers [12] ${ }^{2}$ DaBreo \& Rogers [14] 
Table 3: Monotonic test results per wall configuration (average values)

\begin{tabular}{|c|c|c|c|c|c|c|c|c|}
\hline Specimen(s) & $\begin{array}{c}\mathrm{S}_{\mathrm{u}} \\
(\mathrm{kN} / \mathrm{m})\end{array}$ & $\begin{array}{c}\Delta_{\text {net, } 0.4 \mathrm{u}} \\
(\mathbf{m m})\end{array}$ & $\begin{array}{c}\theta_{\text {net }, 0.4 u} \\
\text { (rad) }\end{array}$ & $\begin{array}{l}\Delta_{\text {net,u }} \\
(\mathbf{m m})\end{array}$ & $\begin{array}{r}\theta_{\text {net,u }} \\
(\text { rad) }\end{array}$ & $\begin{array}{c}\Delta_{\text {net, }, 0.8 \mathrm{u}} \\
(\mathbf{m m})\end{array}$ & $\begin{array}{c}\theta_{\text {net, }, 0.8 u} \\
\text { (rad) }\end{array}$ & $\begin{array}{l}\text { Energy } \\
\text { (joules) }\end{array}$ \\
\hline $1 \mathrm{M}-\mathrm{a}, \mathrm{b}, \mathrm{c}^{1}$ & 6.51 & 2.72 & 0.00111 & 26.4 & 0.0108 & 48.6 & 0.0199 & 325 \\
\hline $2 \mathrm{M}-\mathrm{a}, \mathrm{b}^{1}$ & 10.0 & 3.99 & 0.00164 & 47.9 & 0.0196 & 95.2 & 0.0390 & 1015 \\
\hline $3 M-a, b^{1}$ & 5.51 & 3.00 & 0.00123 & 35.6 & 0.0146 & 58.9 & 0.0241 & 341 \\
\hline $4 \mathrm{M}-\mathrm{a}, \mathrm{b}^{2}$ & 11.0 & 2.56 & 0.00105 & 36.1 & 0.0148 & 65.3 & 0.0268 & 764 \\
\hline $5 \mathrm{M}-\mathrm{a}, \mathrm{b}^{2}$ & 13.8 & 3.04 & 0.00125 & 39.1 & 0.0160 & 58.5 & 0.0240 & 847 \\
\hline $5 \mathrm{M}-\mathrm{c}^{2}$ & 17.2 & 4.76 & 0.00195 & 53.3 & 0.0219 & $100.0^{4}$ & $0.0410^{4}$ & 1813 \\
\hline $6 \mathrm{M}-\mathrm{a}, \mathrm{b}^{2}$ & 16.7 & 4.06 & 0.00166 & 33.6 & 0.0138 & 81.5 & 0.0334 & 1435 \\
\hline $6 \mathrm{M}-\mathrm{c}^{2}$ & 19.1 & 4.20 & 0.00172 & 40.3 & 0.0165 & 58.2 & 0.0239 & 1126 \\
\hline $7 \mathrm{M}-\mathrm{a}^{2}$ & 10.4 & 3.35 & 0.00137 & 23.6 & 0.0097 & 52.3 & 0.0214 & 537 \\
\hline $8 \mathrm{M}-\mathrm{a}, \mathrm{b}^{1}$ & 12.9 & 5.27 & 0.00216 & 62.2 & 0.0255 & $100.0^{4}$ & $0.0410^{4}$ & 676 \\
\hline $9 M-a, b^{1}$ & 14.7 & 6.05 & 0.00248 & 54.5 & 0.0223 & 78.9 & 0.0323 & 583 \\
\hline $9 \mathrm{M}-\mathrm{c}^{1}$ & 18.3 & 7.28 & 0.00298 & 88.5 & 0.0363 & $100.0^{4}$ & $0.0410^{4}$ & 937 \\
\hline $10 \mathrm{M}-\mathrm{a}^{1}$ & 10.5 & 4.20 & 0.00172 & 44.2 & 0.0181 & $100.0^{4}$ & $0.0410^{4}$ & 557 \\
\hline $11 \mathrm{M}-\mathrm{a}, \mathrm{b}^{1}$ & 15.3 & 3.33 & 0.00136 & 27.3 & 0.0112 & 53.1 & 0.0218 & 1666 \\
\hline $12 \mathrm{M}-\mathrm{a}^{2}$ & 14.4 & 2.21 & 0.00091 & 26.1 & 0.0107 & 69.8 & 0.0286 & 1619 \\
\hline $13 \mathrm{M}-\mathrm{a}^{2}$ & 18.5 & 3.67 & 0.00150 & 37.5 & 0.0154 & 58.7 & 0.0240 & 1683 \\
\hline $14 \mathrm{M}-\mathrm{a}^{2}$ & 15.2 & 3.07 & 0.00126 & 28.0 & 0.0115 & 30.3 & 0.0124 & 439 \\
\hline $14 \mathrm{M}-\mathrm{b}^{2}$ & 13.5 & 2.82 & 0.00116 & 29.9 & 0.0123 & 38.8 & 0.0159 & 538 \\
\hline $14 \mathrm{M}-\mathrm{c}^{2}$ & 13.7 & 3.18 & 0.00130 & 29.1 & 0.0119 & 71.1 & 0.0292 & 961 \\
\hline $14 \mathrm{M}-\mathrm{d}^{2}$ & 14.8 & 3.77 & 0.00155 & 36.7 & 0.0150 & 70.1 & 0.0287 & 1037 \\
\hline $15 \mathrm{M}-\mathrm{a}^{2}$ & 13.8 & 3.56 & 0.00146 & 35.9 & 0.0147 & 56.5 & 0.0232 & 803 \\
\hline $16 \mathrm{M}-\mathrm{a}^{2}$ & 9.91 & 3.08 & 0.00126 & 31.4 & 0.0129 & 61.0 & 0.0250 & 1242 \\
\hline $17 \mathrm{M}-\mathrm{a}, \mathrm{b}^{1}$ & 7.75 & 4.30 & 0.00176 & 23.9 & 0.0098 & 35.2 & 0.0144 & 265 \\
\hline $18 \mathrm{M}-\mathrm{a}^{1}$ & 4.58 & 3.18 & 0.00130 & 33.2 & 0.0136 & 64.3 & 0.0263 & 620 \\
\hline B1-M ${ }^{3}$ & 34.0 & 7.03 & 0.00288 & 40.7 & 0.0167 & 74.3 & 0.0305 & 2453 \\
\hline $\mathrm{B} 2-\mathrm{M}^{3}$ & 16.9 & 6.13 & 0.00251 & 47.6 & 0.0195 & 68.3 & 0.0280 & 1161 \\
\hline B3-M ${ }^{3}$ & 19.4 & 6.98 & 0.00286 & 35.8 & 0.0147 & 51.2 & 0.0210 & 922 \\
\hline $\mathrm{B} 4-\mathrm{M}^{3}$ & 16.8 & 4.02 & 0.00165 & 43.2 & 0.0177 & 54.0 & 0.0221 & 896 \\
\hline B5-M ${ }^{3}$ & 12.0 & 5.62 & 0.00230 & 35.5 & 0.0145 & 55.9 & 0.0229 & 662 \\
\hline B6-M $\mathrm{M}^{3}$ & 9.31 & 3.13 & 0.00128 & 28.7 & 0.0118 & 66.0 & 0.0270 & 643 \\
\hline B7-M ${ }^{3}$ & 28.0 & 6.79 & 0.00278 & 39.7 & 0.0163 & 63.8 & 0.0262 & 1725 \\
\hline B8-M ${ }^{3}$ & 14.5 & 3.56 & 0.00146 & 26.6 & 0.0109 & 38.6 & 0.0158 & 548 \\
\hline
\end{tabular}

${ }^{1}$ Balh \& Rogers [13] $\quad{ }^{2}$ Ong-Tone \& Rogers [12] $\quad{ }^{3}$ DaBreo \& Rogers [14] $\quad{ }^{4} 4 \%$ drift limit reached 
Table 4: Reversed cyclic test results per wall configuration (average values for positive cycles)

\begin{tabular}{|c|c|c|c|c|c|c|c|c|}
\hline Specimen & $\begin{array}{c}\mathrm{Su}_{\mathbf{u}} \\
(\mathbf{k N} / \mathbf{m})\end{array}$ & $\begin{array}{c}\Delta_{\text {net }, 0.4 u^{+}} \\
(\mathbf{m m})\end{array}$ & $\begin{array}{c}\theta_{\text {net, } 0.4 u^{+}} \\
\text {(rad) }\end{array}$ & $\begin{array}{l}\Delta \Delta_{\text {net }, \mathbf{u}^{+}} \\
(\mathbf{m m})\end{array}$ & $\begin{array}{l}\theta_{\text {net, u+ }} \\
\text { (rad) }\end{array}$ & $\begin{array}{c}\Delta_{\text {net, }, 0.8 u^{+}} \\
(\mathbf{m m})\end{array}$ & $\begin{array}{c}\theta_{\text {net, }, 0.8 u}+ \\
\text { (rad) }\end{array}$ & $\begin{array}{c}\text { Energy }^{4} \\
\text { (joules) }\end{array}$ \\
\hline $1 \mathrm{C}-\mathrm{a}, \mathrm{b}^{1}$ & 6.23 & 2.90 & 0.00119 & 27.0 & 0.0110 & 45.8 & 0.0188 & 296 \\
\hline $2 \mathrm{C}-\mathrm{a}, \mathrm{b}^{1}$ & 10.9 & 4.30 & 0.00176 & 29.3 & 0.0120 & 88.6 & 0.0363 & 1019 \\
\hline $3 C-a, c^{1}$ & 5.98 & 2.95 & 0.00121 & 39.7 & 0.0163 & 62.0 & 0.0254 & 400 \\
\hline $4 C-a, b^{2}$ & 12.4 & 3.65 & 0.00150 & 30.9 & 0.0127 & 51.0 & 0.0209 & 641 \\
\hline $5 C-a, b^{2}$ & 14.7 & 4.00 & 0.00164 & 31.1 & 0.0127 & 56.9 & 0.0233 & 850 \\
\hline $6 C-a, b^{2}$ & 17.6 & 4.55 & 0.00186 & 32.9 & 0.0135 & 66.3 & 0.0272 & 1200 \\
\hline $8 C-a, b^{1}$ & 13.7 & 5.65 & 0.00232 & 74.1 & 0.0304 & 90.3 & 0.0370 & 638 \\
\hline $9 C-a, b^{1}$ & 16.1 & 7.95 & 0.00326 & 56.1 & 0.0230 & 99.7 & 0.0408 & 828 \\
\hline $11 \mathrm{M}-\mathrm{a}, \mathrm{b}^{1}$ & 16.2 & 2.95 & 0.00121 & 26.9 & 0.0110 & 50.5 & 0.0207 & 1707 \\
\hline $\mathrm{B} 1-\mathrm{R}^{3}$ & 31.2 & 7.20 & 0.00295 & 30.7 & 0.0126 & 61.4 & 0.0252 & 1842 \\
\hline $\mathrm{B} 2-\mathrm{R}^{3}$ & 16.6 & 4.90 & 0.00201 & 42.1 & 0.0172 & 63.4 & 0.0260 & 1075 \\
\hline B3-R ${ }^{3}$ & 20.0 & 5.00 & 0.00205 & 29.8 & 0.0122 & 48.3 & 0.0198 & 940 \\
\hline $\mathrm{B} 4-\mathrm{R}^{3}$ & 16.0 & 3.60 & 0.00148 & 29.6 & 0.0121 & 40.5 & 0.0166 & 634 \\
\hline B5-R ${ }^{3}$ & 12.1 & 4.10 & 0.00168 & 23.0 & 0.0094 & 34.5 & 0.0141 & 402 \\
\hline B6- $\mathrm{R}^{3}$ & 9.34 & 3.20 & 0.00131 & 27.1 & 0.0111 & 42.3 & 0.0173 & 401 \\
\hline
\end{tabular}

${ }^{1}$ Balh \& Rogers [13] ${ }^{2}$ Ong-Tone \& Rogers [12] $\quad{ }^{3}$ DaBreo \& Rogers [14] $\quad{ }^{4}$ Energy calculated as area within the backbone curve of the positive displacement cycles 
Table 5: Reversed cyclic test results per wall configuration (average values for negative cycles)

\begin{tabular}{|c|c|c|c|c|c|c|c|c|}
\hline Specimen & $\begin{array}{c}\mathrm{S}_{\mathrm{u}-} \\
(\mathrm{kN} / \mathrm{m})\end{array}$ & $\begin{array}{c}\Delta_{\text {net, } 0.4 u-} \\
(\mathbf{m m})\end{array}$ & $\begin{array}{c}\theta_{\text {net }, 0.4 u-} \\
\text { (rad) }\end{array}$ & $\begin{array}{l}\Delta \text { net,u- } \\
(\mathbf{m m})\end{array}$ & $\begin{array}{l}\theta_{\text {net,u- }} \\
\text { (rad) }\end{array}$ & $\begin{array}{c}\Delta_{\text {net, }, 0.8 u-} \\
(\mathbf{m m})\end{array}$ & $\begin{array}{c}\theta_{\text {net, } 0.8 u-} \\
\text { (rad) }\end{array}$ & $\begin{array}{c}\text { Energy }{ }^{4} \\
\text { (joules) }\end{array}$ \\
\hline $1 \mathrm{C}-\mathrm{a}, \mathrm{b}^{1}$ & $\begin{array}{l}-6.33 \\
\end{array}$ & -3.00 & -0.00123 & -21.2 & -0.0087 & $\begin{array}{l}-37.4 \\
\end{array}$ & -0.0153 & 237 \\
\hline 2C-a,b1 & -10.7 & -3.90 & -0.00160 & -33.4 & -0.0137 & -86.4 & -0.0354 & 1005 \\
\hline $3 C-a, c^{1}$ & -5.88 & -3.35 & -0.00137 & -31.5 & -0.0129 & -50.6 & -0.0207 & 168 \\
\hline $4 C-a, b^{2}$ & -11.8 & -3.25 & -0.00133 & -30.8 & -0.0126 & -46.1 & -0.0189 & 542 \\
\hline $5 C-a, b^{2}$ & -14.0 & -3.55 & -0.00145 & -29.1 & -0.0119 & -56.5 & -0.0231 & 789 \\
\hline 6C-a,b㬏 & -17.0 & -4.95 & -0.00203 & -33.3 & -0.0137 & -69.8 & -0.0286 & 1189 \\
\hline 8C-a,b ${ }^{1}$ & -13.5 & -5.75 & -0.00236 & -64.9 & -0.0266 & -94.0 & -0.0385 & 650 \\
\hline 9C-a,b ${ }^{1}$ & -15.5 & -7.55 & -0.00309 & -66.6 & -0.0273 & -100.0 & -0.0410 & 764 \\
\hline 11M-a,b ${ }^{1}$ & -16.0 & -3.30 & -0.00135 & -28.2 & -0.0115 & -54.7 & -0.0224 & 1814 \\
\hline $\mathrm{B} 1-\mathrm{R}^{3}$ & -31.9 & -9.60 & -0.00393 & -58.8 & -0.0241 & -78.8 & -0.0323 & 2407 \\
\hline $\mathrm{B} 2-\mathrm{R}^{3}$ & -17.1 & -6.00 & -0.00246 & -59.5 & -0.0244 & -77.4 & -0.0317 & 1381 \\
\hline B3-R ${ }^{3}$ & -21.4 & -5.40 & -0.00221 & -29.8 & -0.0122 & -41.6 & -0.0170 & 846 \\
\hline $\mathrm{B} 4-\mathrm{R}^{3}$ & -17.0 & -4.00 & -0.00164 & -31.9 & -0.0131 & -44.7 & -0.0183 & 747 \\
\hline B5-R ${ }^{3}$ & -12.7 & -4.40 & -0.00180 & -30.7 & -0.0126 & -47.8 & -0.0196 & 610 \\
\hline $\mathrm{B} 6-\mathrm{R}^{3}$ & -9.63 & -4.70 & -0.00193 & -26.8 & -0.0110 & -43.8 & -0.0180 & 408 \\
\hline
\end{tabular}

${ }^{1}$ Balh \& Rogers [13] $\quad{ }^{2}$ Ong-Tone \& Rogers [12] $\quad{ }^{3}$ DaBreo \& Rogers [14] $\quad{ }^{4}$ Energy calculated as area within the backbone curve of the negative displacement cycles 
Figure 1: Typical cold-formed steel framed building with steel sheathed shear walls (photo courtesy of J. Ellis, Simpson Strong-Tie Co. Inc.)

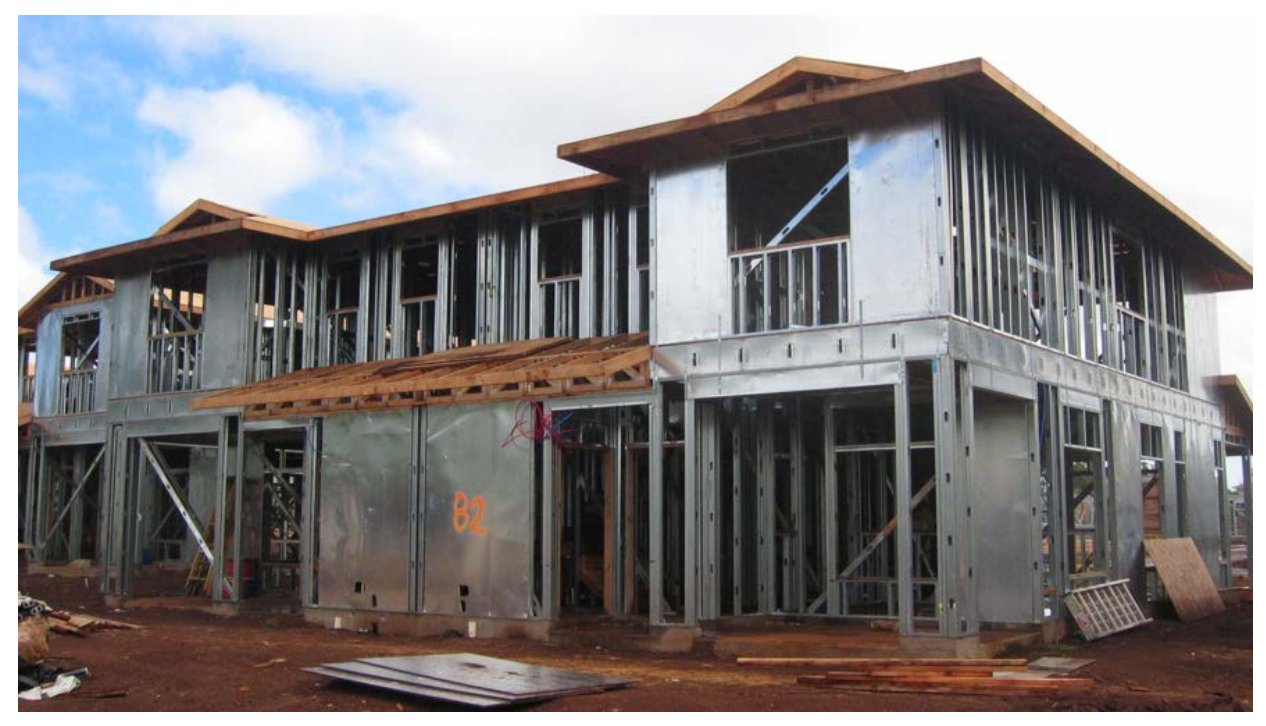


Figure 2: Details of typical $1220 \mathrm{~mm} \times 2440 \mathrm{~mm}$ walls with un-blocked framing (configurations 1 to $7 \& 18)$

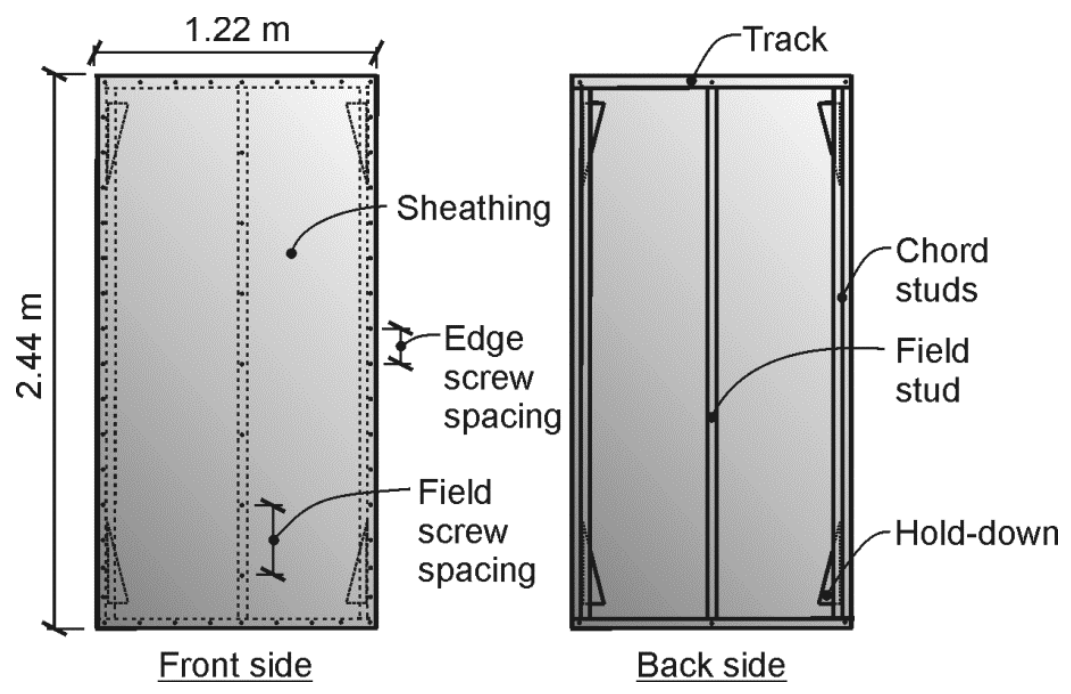


Figure 3: Details of walls with un-blocked framing and lengths of; a) $610 \mathrm{~mm} \times 2440 \mathrm{~mm}$ (configurations 8 to 10), b) $1830 \mathrm{~mm} \times 2440 \mathrm{~mm}$ (configurations $12 \&$ 13), and c) $2440 \mathrm{~mm} \times$ $2440 \mathrm{~mm}$ (configuration 11)

a) $\quad$ b)

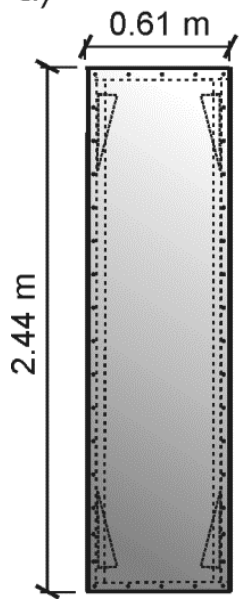

b)

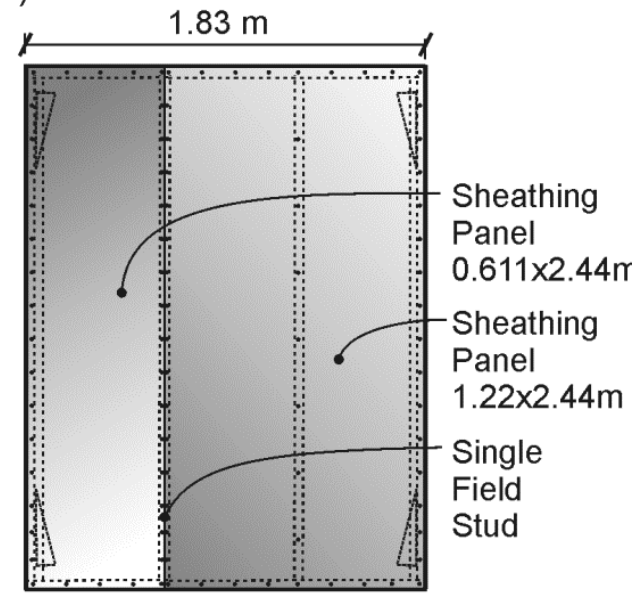

c)

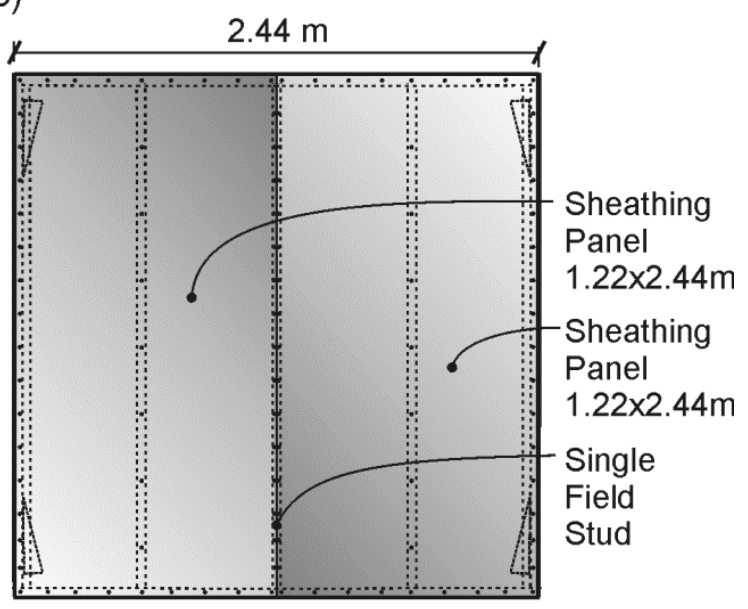


Figure 4: Details of $1220 \mathrm{~mm} \times 2440 \mathrm{~mm}$ configuration 14 walls with framing reinforcement; a) quarter-point bridging and corner gusset plate reinforcement, b) quarter-point bridging

a)

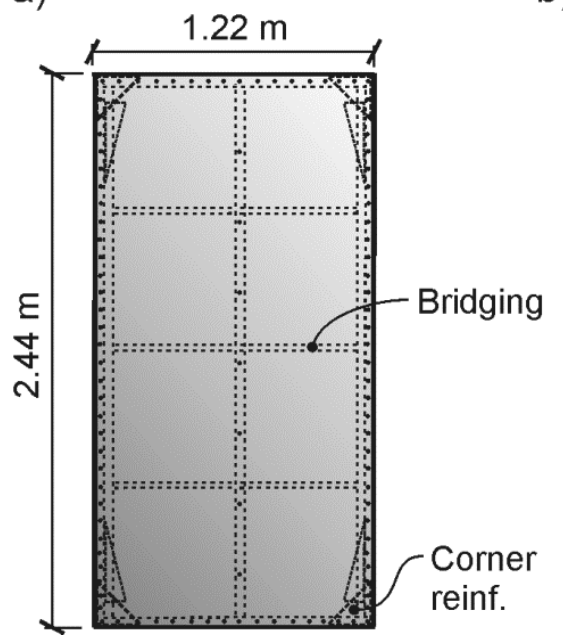

b)

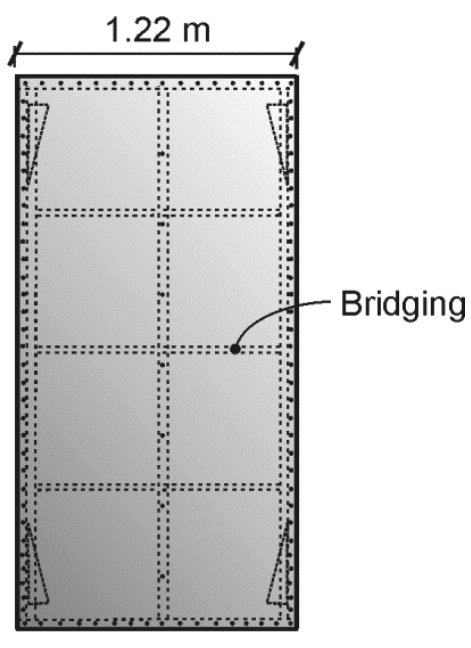


Figure 5: Details of walls with un-blocked framing; a) $1220 \mathrm{~mm} \times 2440 \mathrm{~mm}$ (configuration 15), b) $2440 \mathrm{~mm} \times 2440 \mathrm{~mm}$ (configuration 16), and c) $1220 \mathrm{~mm} \times 2440 \mathrm{~mm}$ (configuration 17)
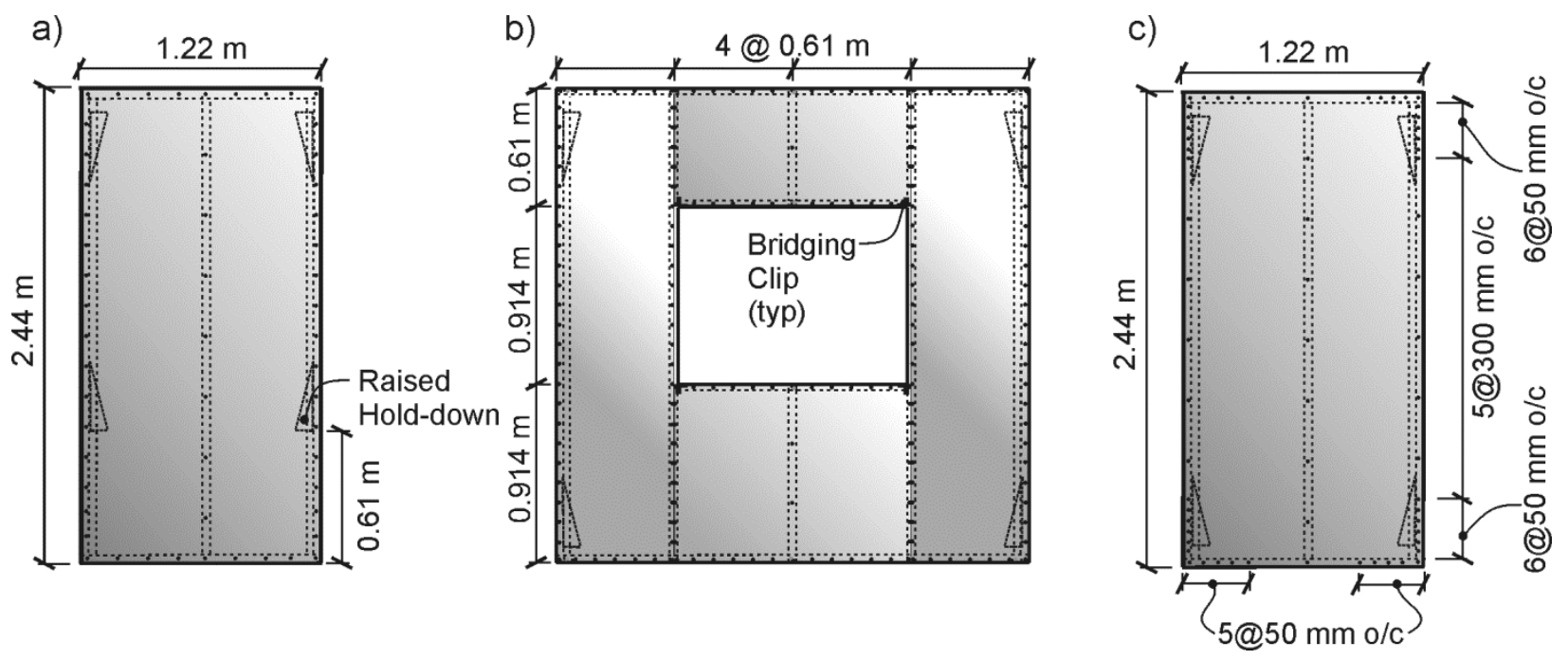
Figure 6: Details of typical $1220 \mathrm{~mm} \times 2440 \mathrm{~mm}$ walls with blocked framing (configurations B1 to B8)

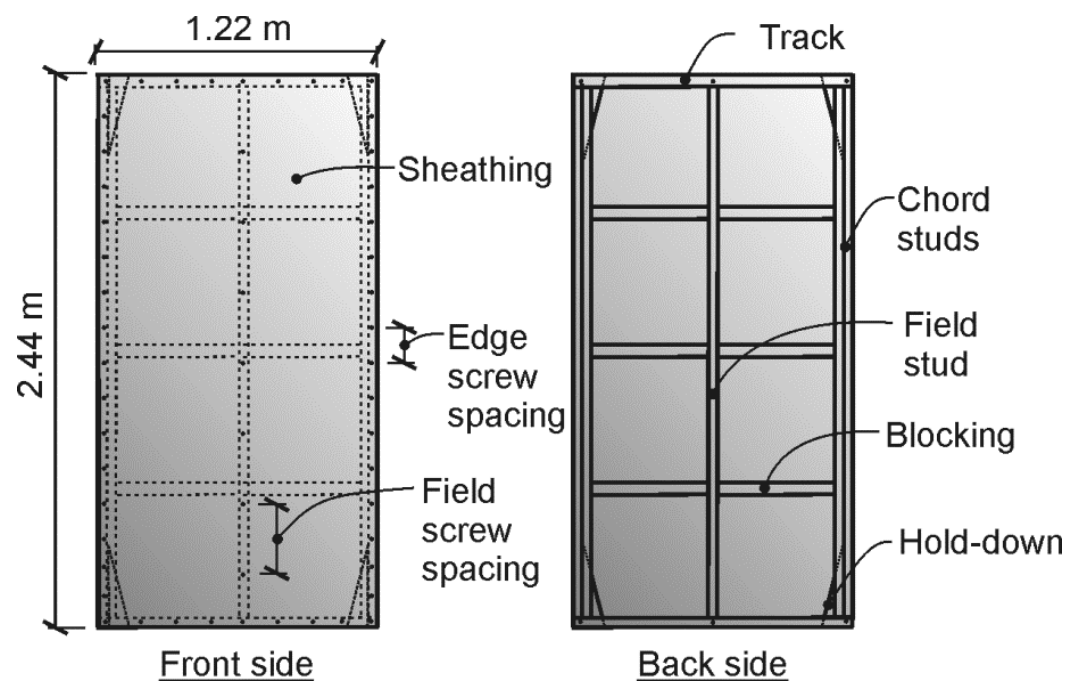


Figure 7: Conceptual schematic drawing of calculation approach for compression force on chord studs

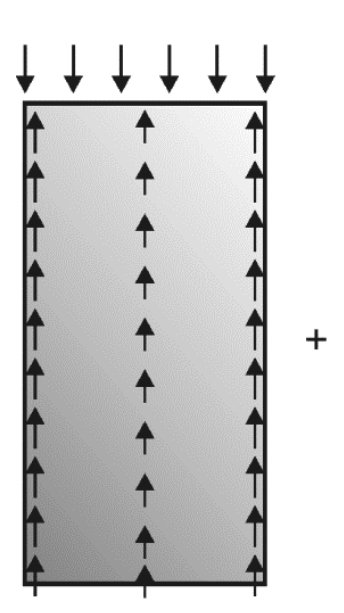

Gravity

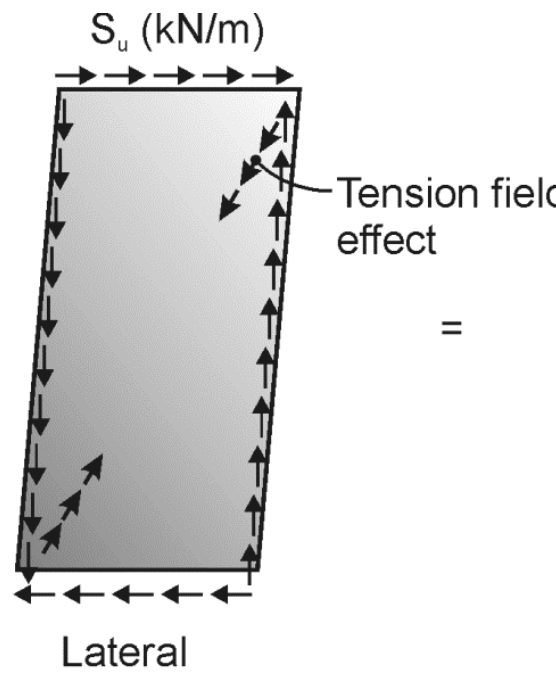

Comp. Chord Stud Forces (kN)

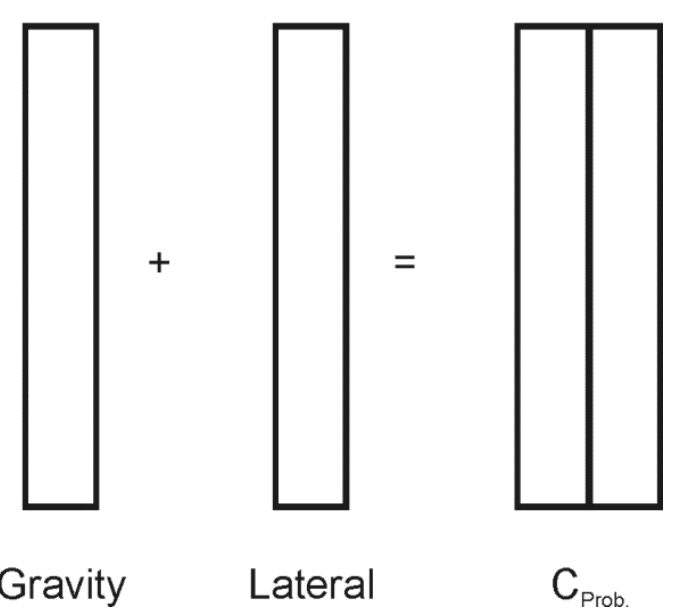


Figure 8: Walls with blocked framing; a) detail of the blocking connection, b) frame prior to installation of sheathing (temporary brace used for alignment purposes)

a)

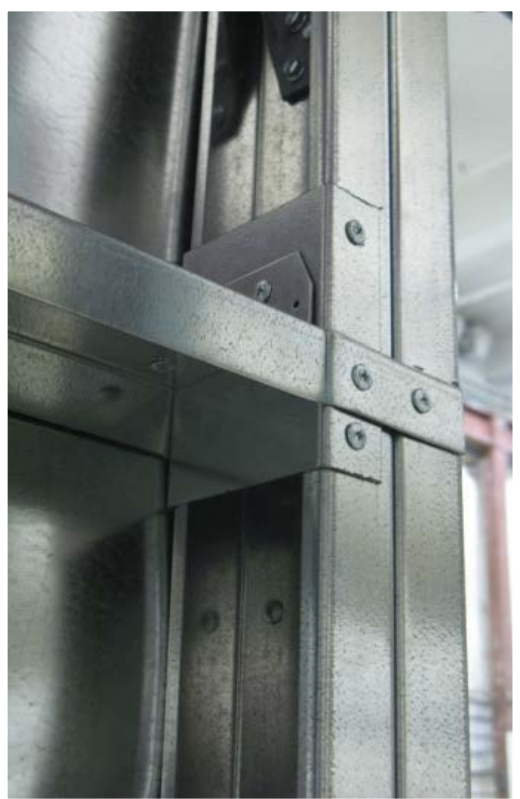

b)

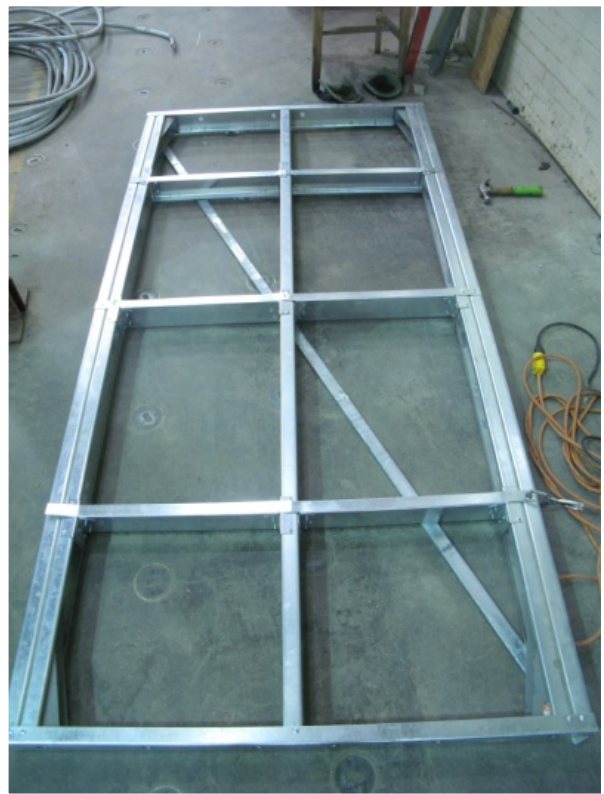


Figure 9: Schematic drawing of test frame with $2440 \mathrm{~mm} \times 2440 \mathrm{~mm}$ shear wall specimen (setup with lateral loading shown)

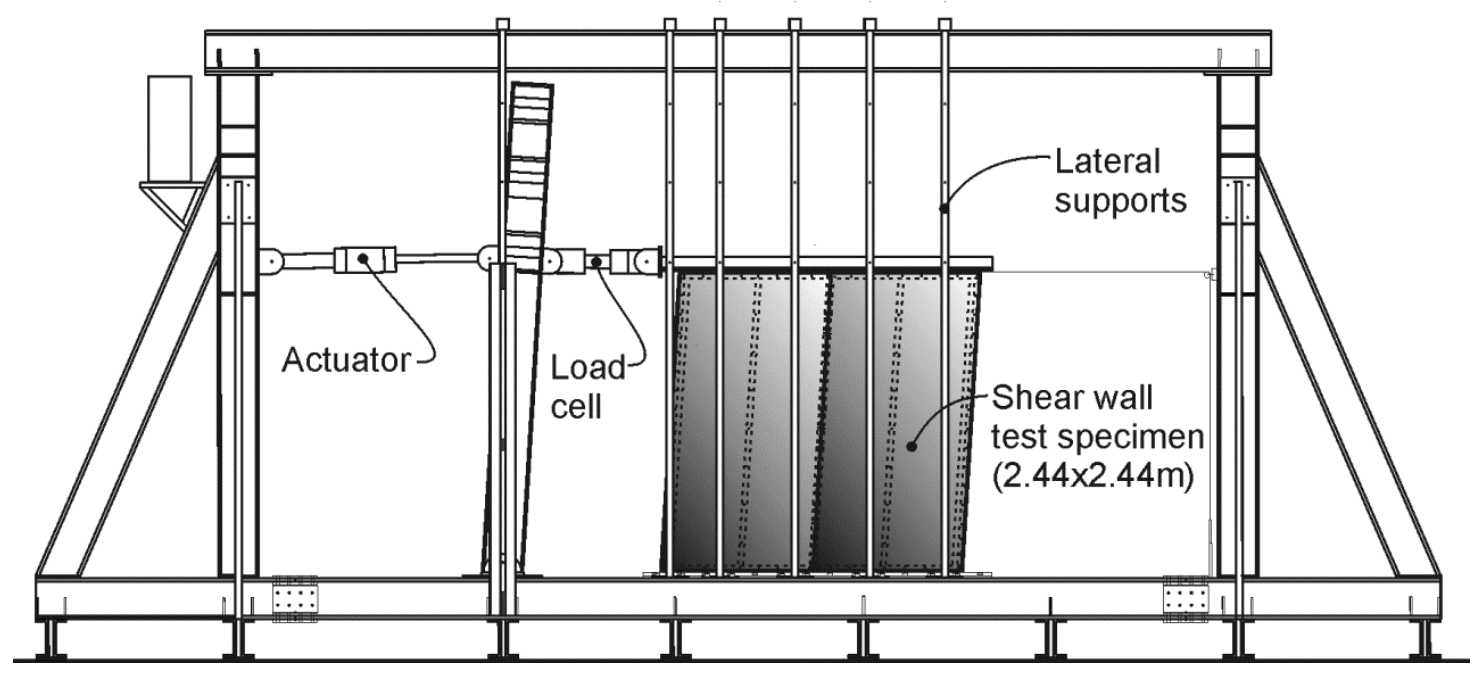


Figure 10: Test frame with $1220 \mathrm{~mm} \times 2440 \mathrm{~mm}$ shear wall specimen (setup with gravity and lateral loading shown); a) overall view, b) spring and roller gravity support system

a)

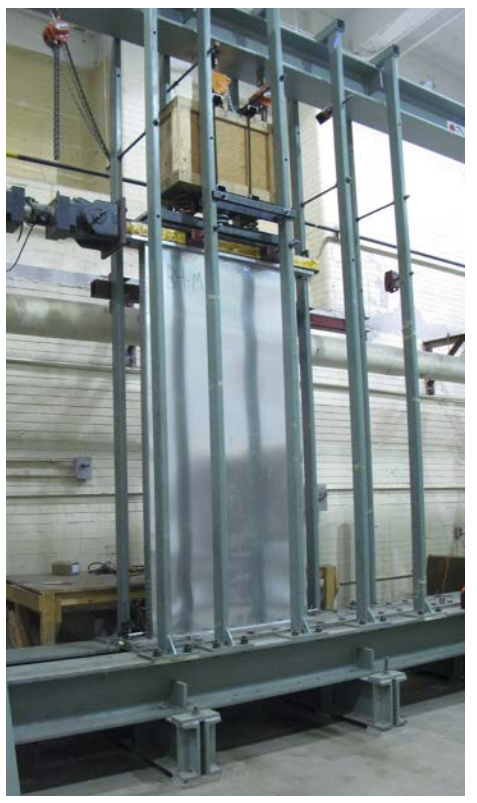

b)

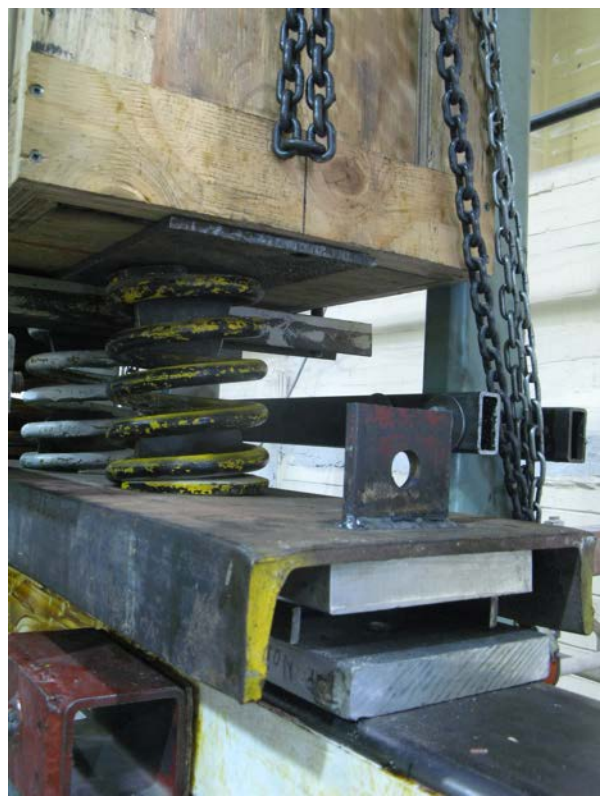


Figure 11: Typical elastic shear buckling and tension field development; a) $1220 \mathrm{~mm}$ x $2440 \mathrm{~mm}$ wall (reversed cyclic loading), b) $2440 \mathrm{~mm}$ x $2440 \mathrm{~mm}$ wall (monotonic loading)

a)

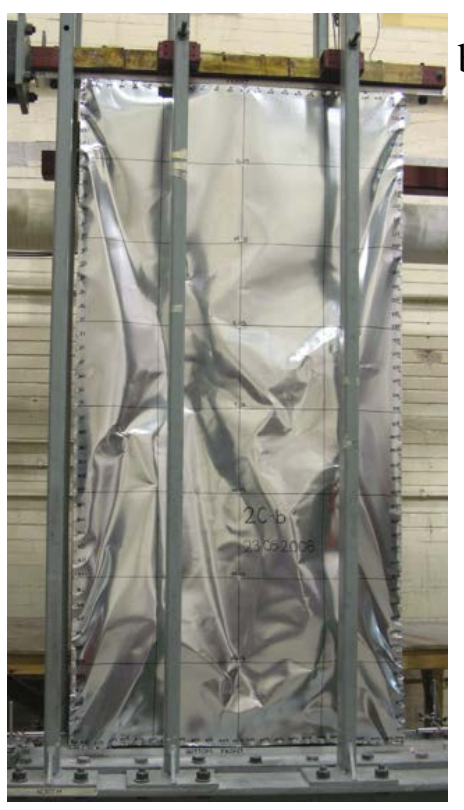

b)

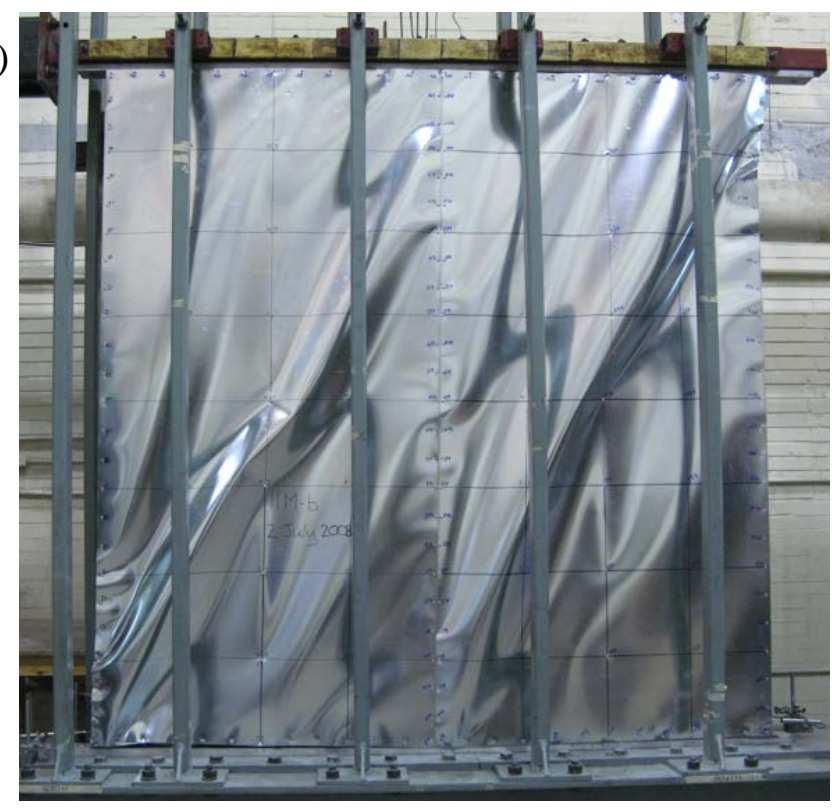


Figure 12: Typical sheathing connection failure modes; a) bearing of sheathing, b) fastener pullthrough, c) fastener pull-out

a)

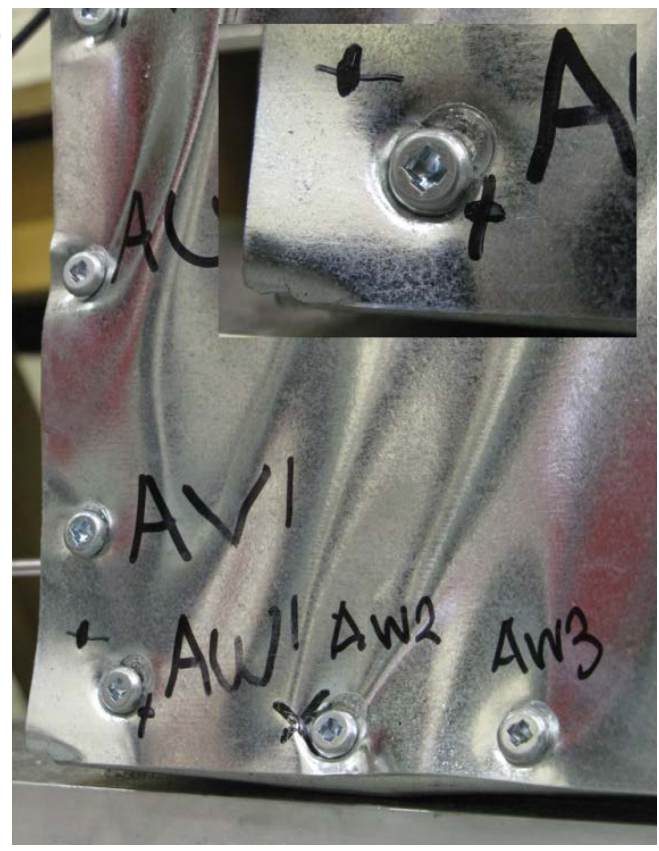

b)

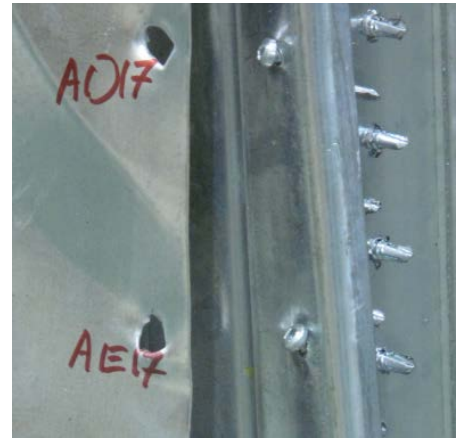

c)

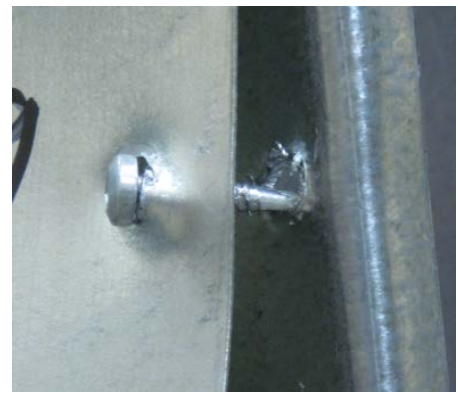


Figure 13: Torsional failure of chord studs in un-blocked walls due to horizontal component of tension field force; a) face view $1220 \mathrm{~mm}$ x $2440 \mathrm{~mm}$ wall (monotonic loading), b) end view 610 mm x 2440 mm wall (monotonic loading).

a)

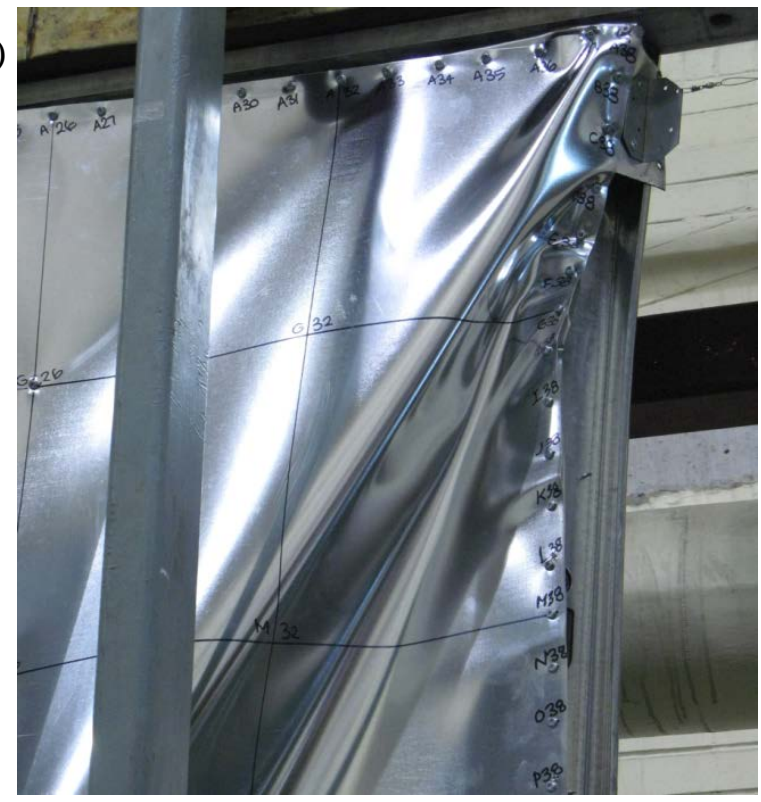

b)

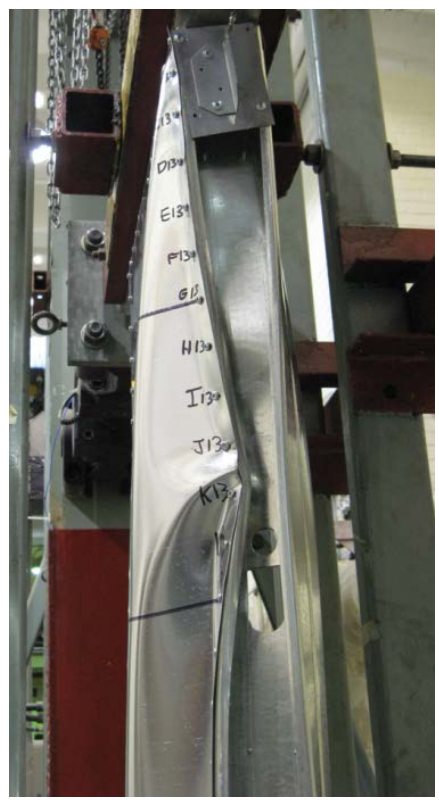


Figure 14: Lateral-torsional buckling of bridging member

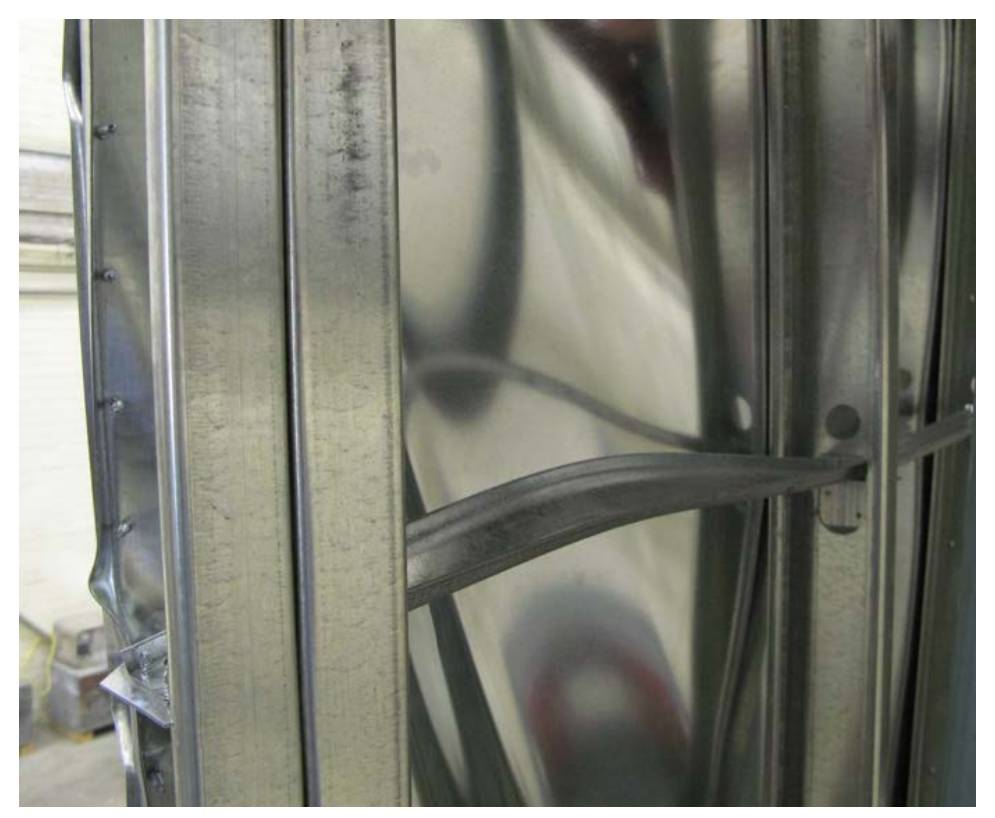


Figure 15: Blocked wall damage; a) tension field and shear buckling during monotonic test, b) out-of-plane stud flange distortion and sheathing connection failure, c) sheathing connection failure
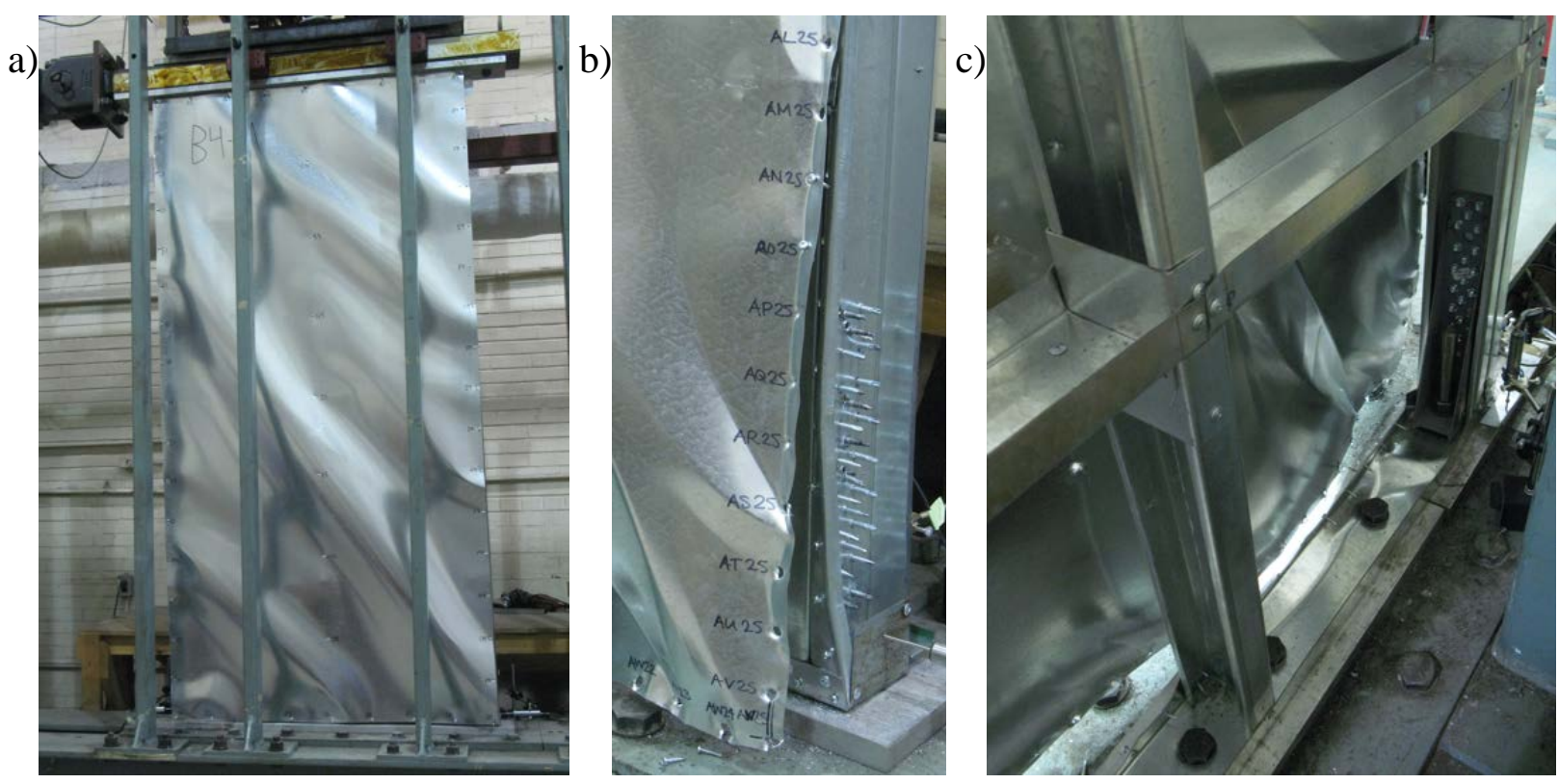
Figure 16: Typical monotonic resistance vs. displacement curve

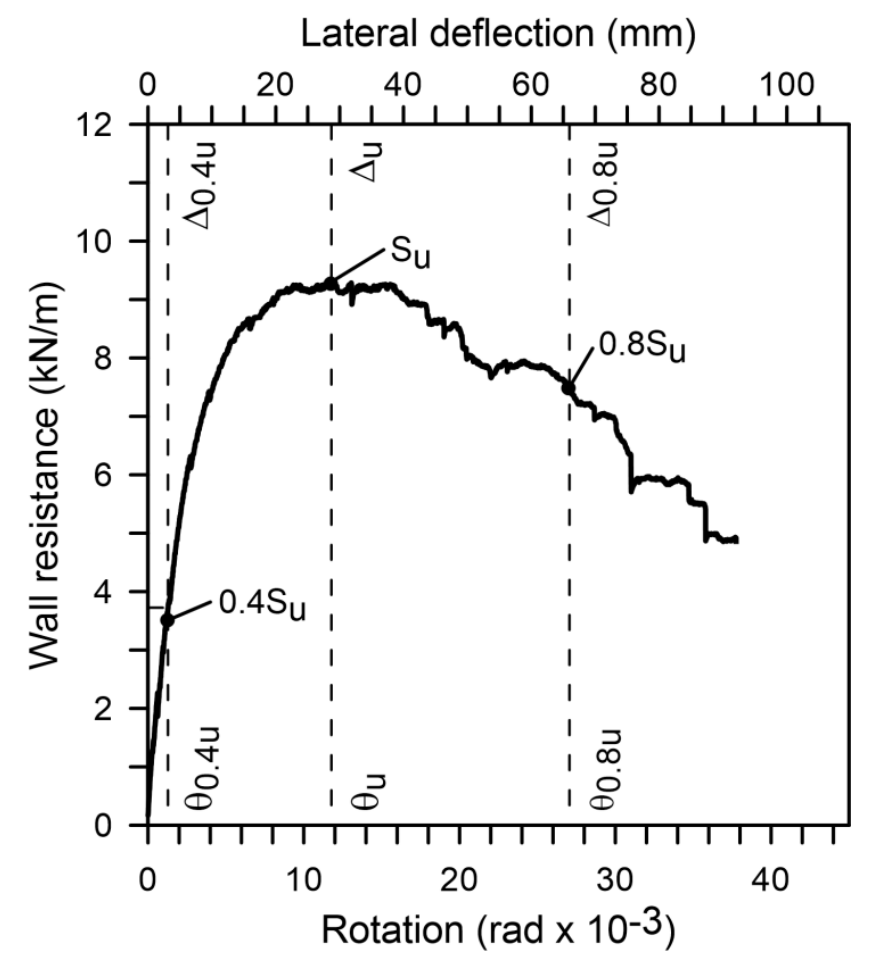


Figure 17: Typical reversed cyclic resistance vs. displacement curve

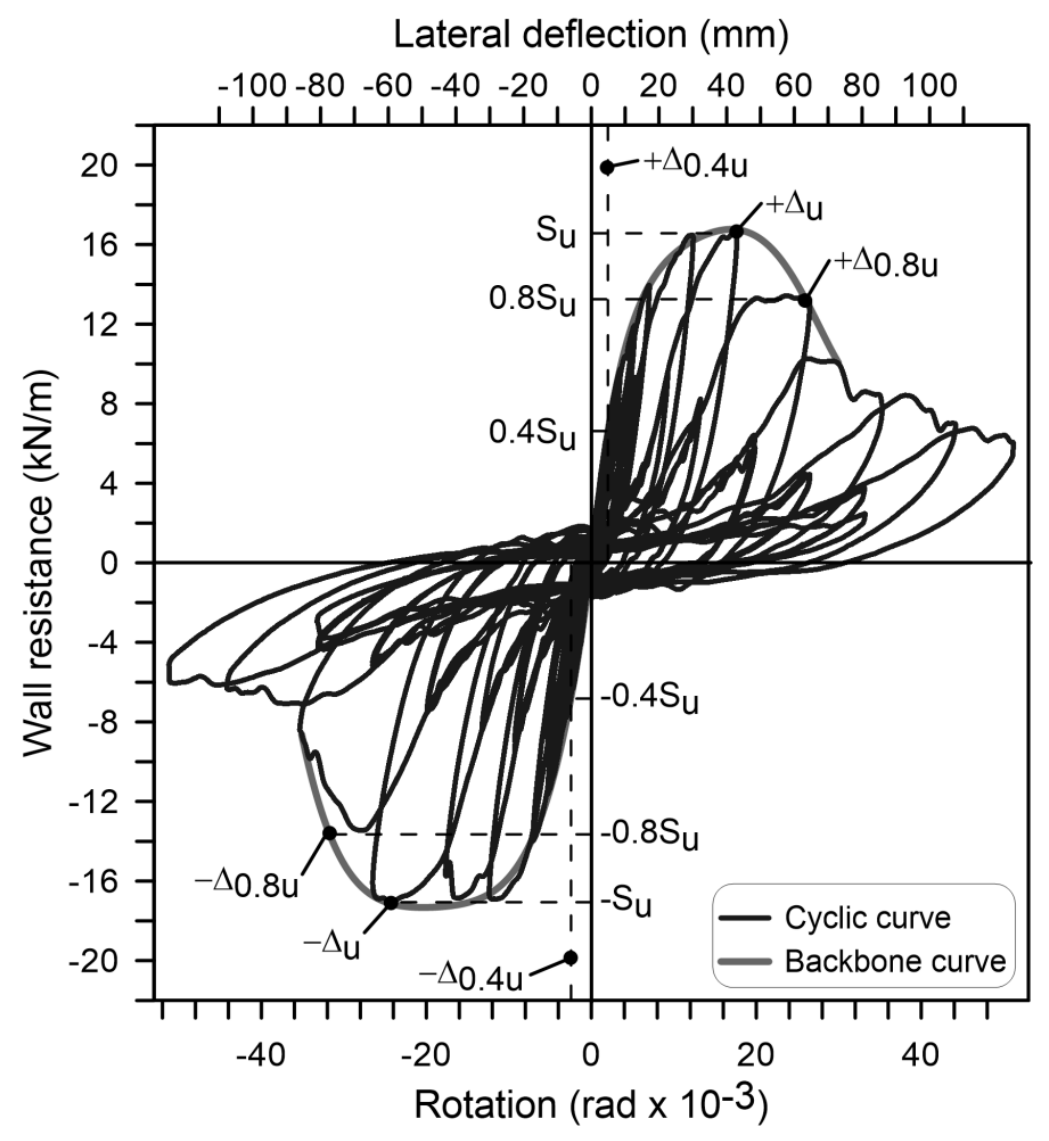


Figure 18: Illustrative comparison of normalized monotonic resistance vs. displacement curves of blocked, bridged and un-blocked walls

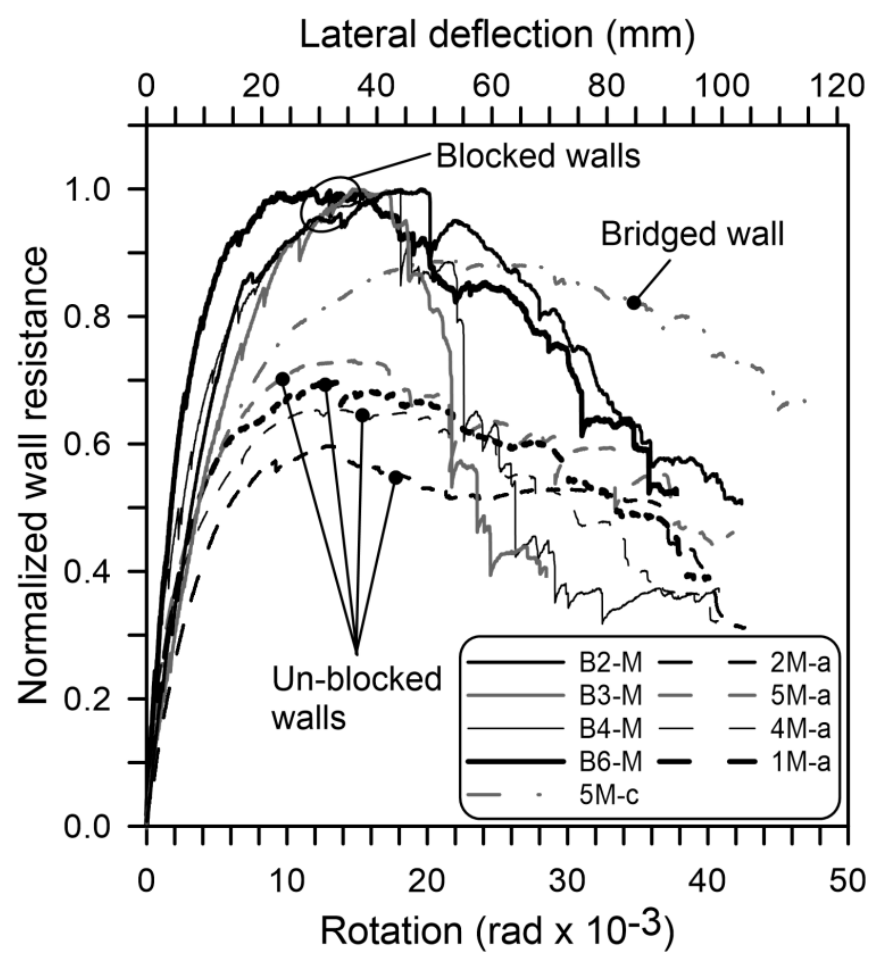


Figure 19: Illustrative comparison of normalized reversed cyclic resistance vs. displacement curves of blocked and un-blocked walls

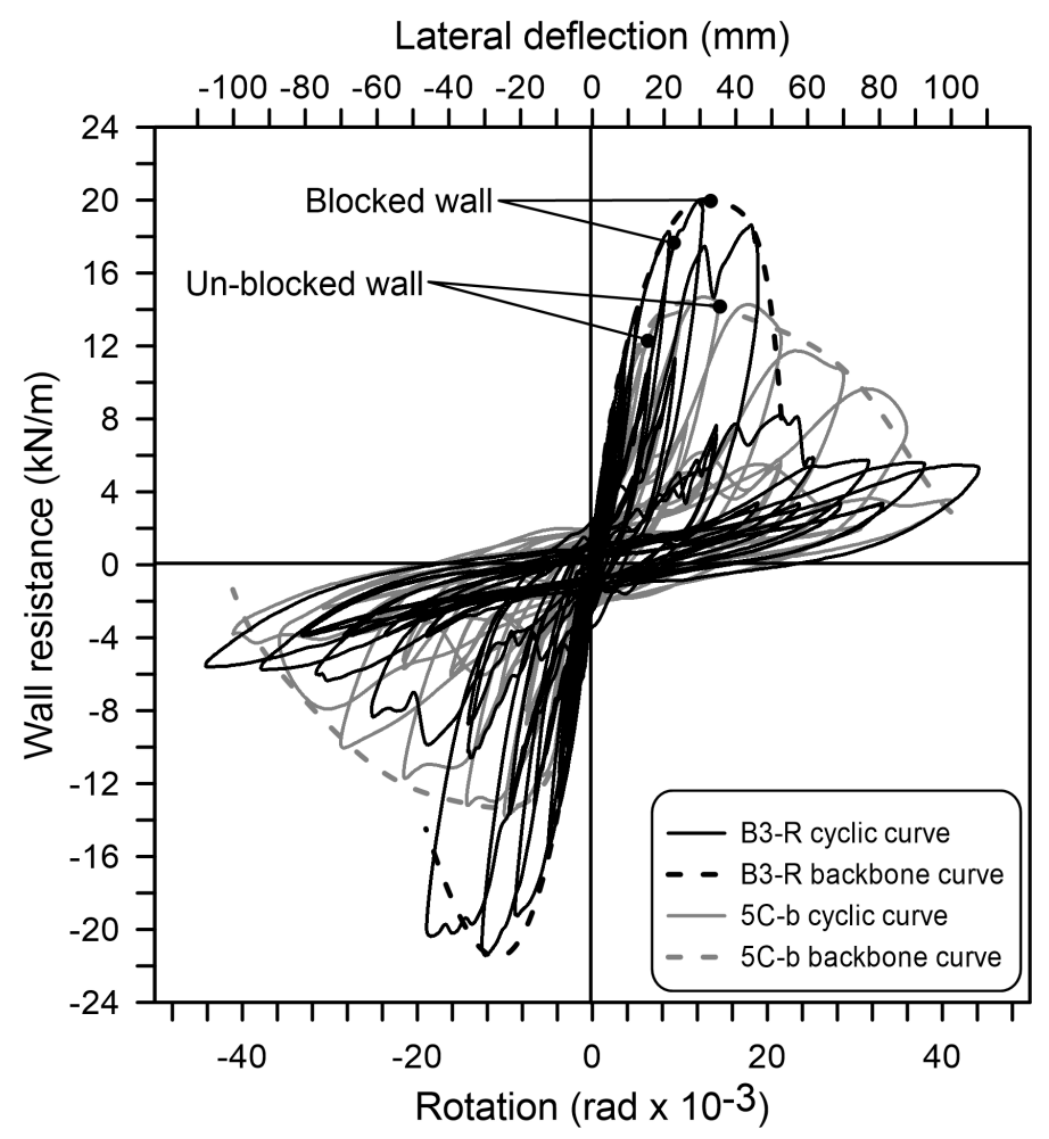

